\title{
Analysis of the Thermal-force Roll Profile Control Ability Under Different Hole Structures and Slot Structures in the RPECT
}

Tingsong Yang

Yanshan University

Jiayang Liu

Yanshan University

Haonan Zhou

Yanshan University

Zhiqiang Xu

Yanshan University

Fengshan Du ( $\nabla$ fsdu@ysu.edu.cn )

Yanshan University

\section{Research Article}

Keywords: Roll profile electromagnetic control technology, hole structure, slot structure, thermal-force roll profile control ability, electromagnetic stick

Posted Date: March 22nd, 2021

DOl: https://doi.org/10.21203/rs.3.rs-322981/v1

License: (1) This work is licensed under a Creative Commons Attribution 4.0 International License.

Read Full License 
1 Analysis of the thermal-force roll profile control ability under

2 different hole structures and slot structures in the RPECT

3 Tingsong Yang ${ }^{\mathrm{a}, \mathrm{b}}$, Jiayang Liu ${ }^{\mathrm{a}, \mathrm{b}}$, Haonan Zhou ${ }^{\mathrm{a}, \mathrm{b}}$, Zhiqiang Xu ${ }^{\mathrm{a}, \mathrm{b}}$, Fengshan Du ${ }^{\mathrm{a}, \mathrm{b},{ }^{*}}$

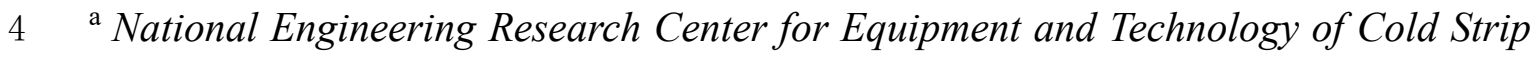

5 Rolling, Yanshan University, Qinhuangdao 066004, Hebei, PR China

6 b College of Mechanical Engineering, Yanshan University, Qinhuangdao, Hebei

$7 \quad 066004$, PR China

$8 *$ Corresponding Author:

9 Fengshan $\mathrm{Du}$,

10 Tel: +8613803354838 .

11 E-mail address: fsdu@ysu.edu.cn

13 Highlights

14 - The effect of different hole structures on roll profile control ability is studied.

- The effect of slot on roundness and roll profile control ability in the RPECT is analysed.

- The configuration method of hole and slot in the RPECT is proposed.

Abstract

Roll profile electromagnetic control technology (RPECT) is a strip flatness control technology based on the flexible control of roll profiles. As the core component, electromagnetic sticks can bulge with the induction heating of induction coils. To ensure the integrity of the coil circuit, the surfaces of the electromagnetic sticks need to be provided with slots. Moreover, the inner hole of the electromagnetic control roll is also needed to install the electromagnetic stick in the roll. The structures of the inner hole and slots affect the local structure of the electromagnetic stick and the 
electromagnetic control roll and then change the roll profile control ability. To research the radial bulging ability, the roundness of bulging, and the composition between the thermal crown and force crown under different holes or slots, a finite element model of circumferential RPECT is established by using the finite element software MARC. After analysis, the results showed that the radial bulging ability and the roundness under the influence of the roll radius were larger than those under the influences of the slot radius and slot amount, and the composition characteristics of the comprehensive roll profile were different under different conditions. Therefore, to achieve accurate roll profile control, the influences of the structures of holes and slots need to be included in the RPECT index.

Keywords: Roll profile electromagnetic control technology, hole structure, slot structure, thermal-force roll profile control ability, electromagnetic stick

\section{Introduction}

Roll profile electromagnetic control technology (RPECT) is a new strip flatness control technology based on the roll profile flexible control method. By the bulging mechanism of the electromagnetic stick (ES) and the internal restraint mechanism of the electromagnetic control roll (ECR), the roll profile of the ECR can be controlled to form a new roll profile with shape control ability. In the control process, the multisegment structure of the ES can be powered by coils of different sections and generate the target roll profile in the corresponding section of the coils to adjust the high-order strip flatness and local strip flatness. Regarding RPECT, researchers have studied this technology and formed a series of research results. Feng et al. [1] proposed a large-size sleeved backup roll based on RPECT and analysed the characteristics of this roll. By researching the induction heating efficiency, energy conversion ability and roll profile, Liu et al. $[2,3]$ designed the structure of an ES with high control performance and built an ECR with five control regions based on a $\varphi 560 \times 2180-\mathrm{mm}$ roll. $\mathrm{Du}$ et al. [4] relied on the principle of RPECT and the new roll profile test 
technology and designed and built a roll profile electromagnetic control experimental platform (RPECEP) that has the ability to test RPECT experimentally. Based on the relationship between the material hardness and elastic modulus, Wang et al. [5] established the FE model of a heterogeneous electromagnetic control roll and proposed the influence of heterogeneity on the characteristics of RPECT. The above studies are the basis of RPECT and promote the development of this technology. However, these studies did not involve the influence of the winding space of coils on the roll profile control ability. In RPECT, the structure of the ES includes the induction zone and contact zone, as shown in Fig. 1. The induction zone can be used to wind the coils, and the contact zone can be used for thermal bulging. To build a closed circuit between the coils and the external power supply, the surface of the contact zone needs to be provided with slots for laying coil wires. The number of slots is twice that of the induction zones to ensure the current input and output. The space of the slots can change the local structure of the ES and then affect the electromagnetic control roll profile.

The ES is the core control element of RPECT and provides thermal-force hybrid drive for roll profile control. Due to the influence of the local structure and local load, the structure of the slots and the roll inner hole can change the roll profile and affect the roll profile control ability. Considering that the expected effect of the equipment can be affected by the local structure, scholars have studied the problems of control abilities in different equipment. Min Jung Lee et al. [6] analysed the combustion characteristics of casting filters with porous media and found that the effective emissivity of porous media was 0.845 ; therefore, the operational safety of this casting filter was confirmed. Based on thermochromic liquid crystal (TLC) technology, Li et al. [7] analysed the film cooling performance on a twist turbine blade under rotation conditions, and the results showed that the film hole diameter of the leading edge has a significant effect on the spanwise average film cooling effectiveness. Enke et al. [8] proposed that the lifetime of axially grooved ammonia heat pipes (HPs) and the HP performance can be affected by the generation of noncondensable gas (NCG) and revealed how the presence of different amounts of NCGs distorted the temperature profile of the pipe. Dai et al. [9] developed a numerical model of the combustion and cooling performance of an aero- 
engine combustor and analysed the ability to reduce the thermal load of thermal barrier coatings when the cooling holes are cylindrical holes, conical holes, fan-shaped holes or console holes. Xu et al. [10] compared and analysed the film cooling characteristics with two structures of slots in a perpendicular cross-flow channel and found that the film cooling effectiveness of slot-sectional diffusion holes is far superior to that of fanshaped holes. This type of research focuses on the specific analysis object, considering the local characteristics to analyse the impact of local characteristics on the overall performance. For this reason, this paper mainly studies the problem of the roll profile control ability and thermal-force hybrid driving ability under different slot structures of the ES and different roll inner holes.

In view of the crucial influence of the local structure of RPECT on the control ability of the ECR and thermal force hybrid driving ability, this paper compared and studied the roundness of the ECR, radial bulging ability of the ECR, stress field of the ECR and temperature field of the ECR under different roll radii, different slot radii and different slot amounts and discussed the thermal crown and force crown of different cases.

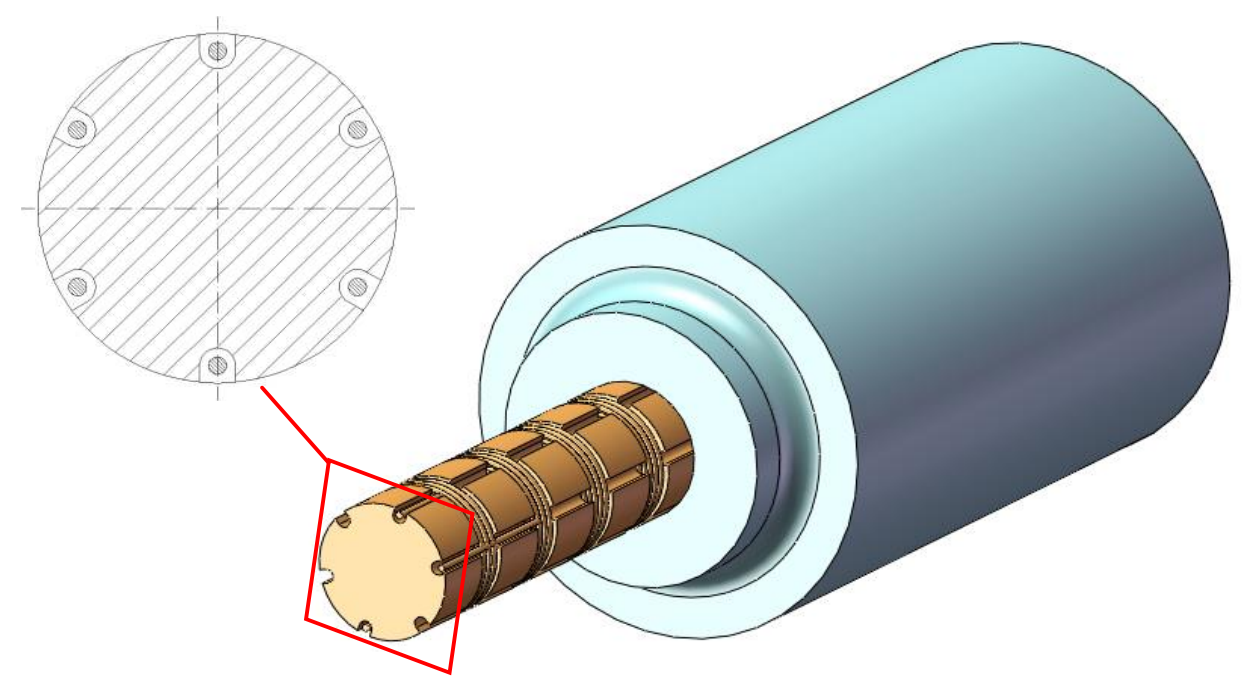

Fig. 1 The structure of the ES and the cross-section of the ES with induction coils

\section{Model establishment and verification}

\subsection{Model establishment}

According to the literature [2], the FE model of RPECT includes electromagnetic field simulation and thermal field simulation, and the relationship between them is 
nonlinear coupling. The FE model includes the ECR, ES, induction coils and air. Based on the theory of electromagnetics and thermodynamics, an electromagnetic-thermalmechanical coupled axisymmetric model has been built by the software MARC in the literature [2-5], as shown in Fig. 2. This model has a high degree of consistency and a small deviation, while the results of the experiment and simulation have been verified in a roll profile electromagnetic control experimental platform. In the bulging process of the ES, heat is generated in the induction zone of the ES when the induction coils are electrified, and then, heat is transmitted to the contact zone of the ES to control the roll profile. The above model can simulate the temperature field of the contact zone and meet the needs of this study.

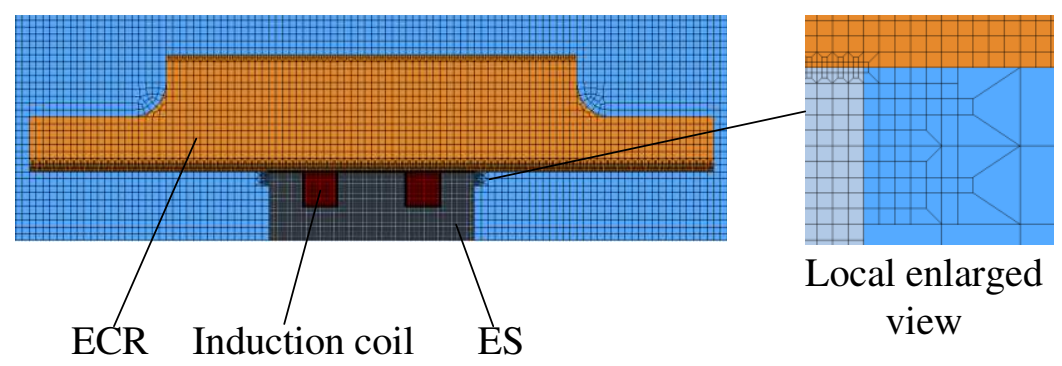

Fig. 2. The electromagnetic-thermal-mechanical coupled axisymmetric model of RPECT

To study the influence of the slot structure on the roll profile control ability, a FE model of circumferential RPECT is established in this paper. The analysis object of this model is the slicing model of the ECR. The model includes the ECR with the ECR inner hole, ES with slots and air, as shown in Fig. 3. 


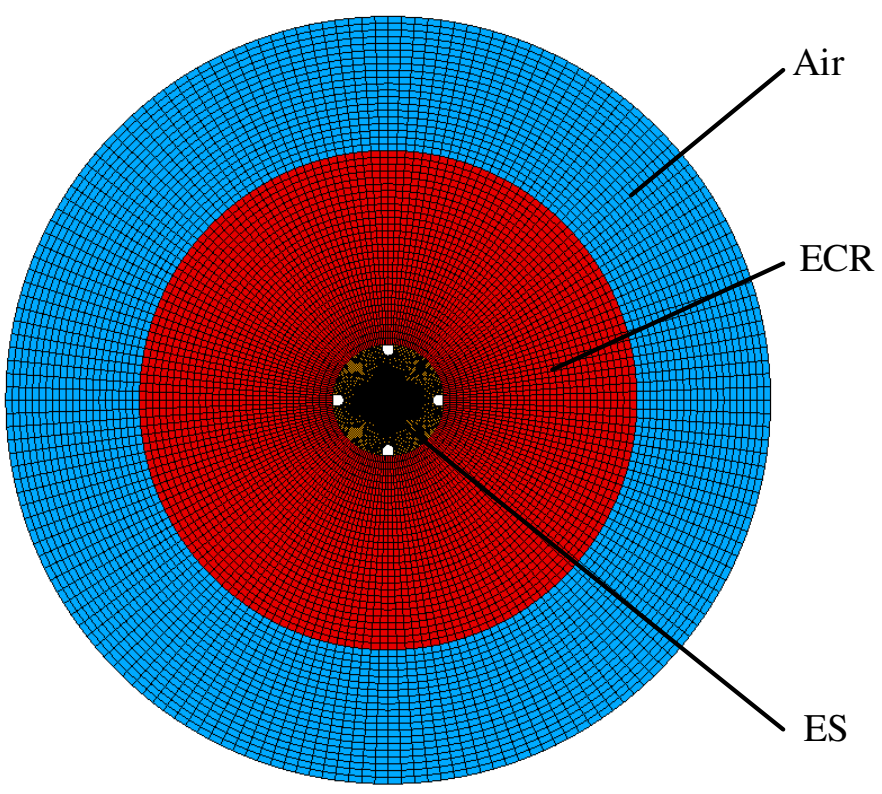

Fig. 3. The FE model of circumferential of RPECT

Considering that the bulging power of RPECT is the thermal bulging of the contact zone of the ES, the heat driving the bulging of the ES is sourced from the induction zone of the ES, and the core zone of the ES is the connected area between the induction zone and the contact zone, as shown in Fig. 4. Therefore, the core zone of the ES can be selected as the thermal boundary of driving bulging to study the circumferential bulging of RPECT in this model. Since the heat transfer inside the ECR has little effect on the temperature field of the core zone of the ES, the temperature variation of the thermal boundary can be derived from the electromagnetic-thermal-mechanical coupled axisymmetric model with the same size.

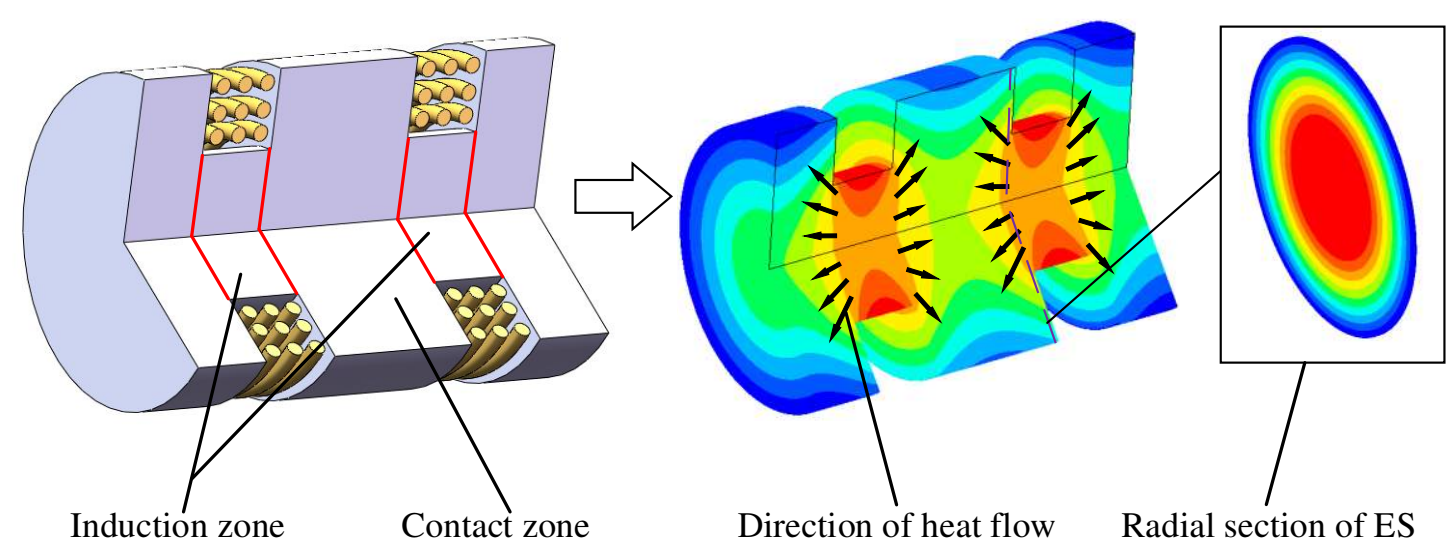

Fig. 4. The connection diagram of ES zones

In the process of $\mathrm{FE}$ calculation, the frequency is $400 \mathrm{~Hz}$, the current density of the sour is $3 \mathrm{~A} / \mathrm{mm}^{2}$, and the contact heat transfer coefficient $\mathrm{h} 1$ is $3 \mathrm{~kW} /\left(\mathrm{m}^{2} \cdot \mathrm{K}\right)$ between 
140 the ES and ECR. The selected range of the roll radius is from $80 \mathrm{~mm}$ to $250 \mathrm{~mm}$, the 141 selected range of the slot radius is from $2.5 \mathrm{~mm}$ to $7.5 \mathrm{~mm}$, and the selected range of 142 the slot amount is from 4 to 8 . Among them, the basic condition parameters of the hole 143 structure and slot structure are as follows: the roll radius is $135 \mathrm{~mm}$, the slot radius is 3 $144 \mathrm{~mm}$, and the slot amount is 4 . According to research in the literature [11], the optimum 145 heat transfer coefficient $\mathrm{h} 2$ is $1 \mathrm{~kW} /\left(\mathrm{m}^{2} \cdot \mathrm{K}\right)$ between the ECR and air. The radiation heat 146 transfer is small enough to be ignored. The original temperature is $30^{\circ} \mathrm{C}$. The material 147 of the ECR and ES is \#45 steel. The thermal properties are shown in Fig. 5. The region 148 within the $25-\mathrm{mm}$ diameter in the core zone of the ES is the thermal boundary of the 149 model, and the temperature variation with the control time can be calculated in the 150 electromagnetic-thermal-mechanical coupled axisymmetric model. The temperature 151 variation can be shown in Fig. 6.

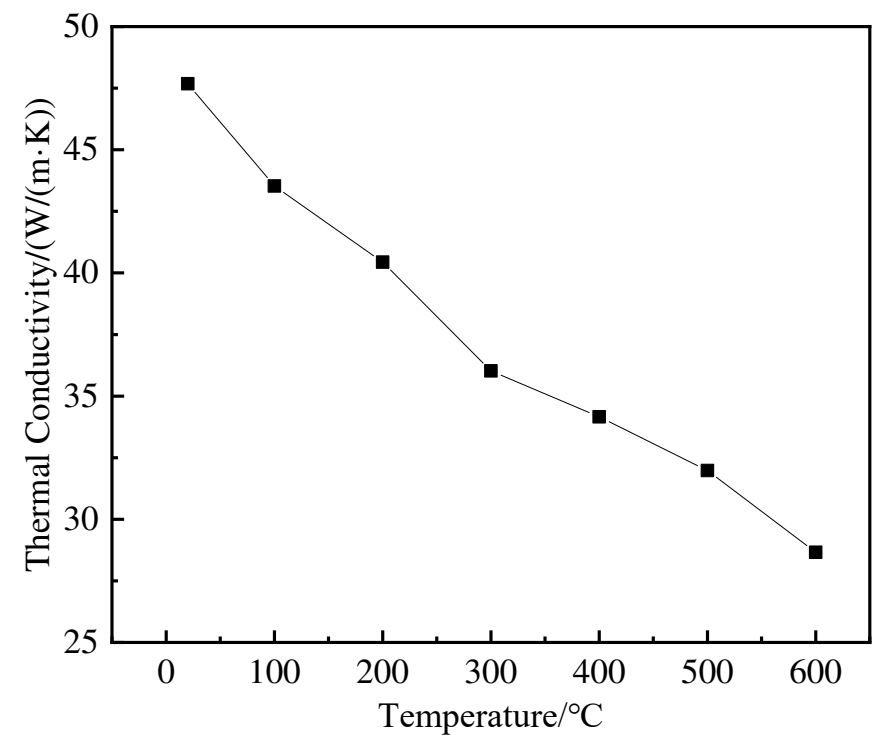

153 Fig. 5. The thermal properties of \#45 steel 


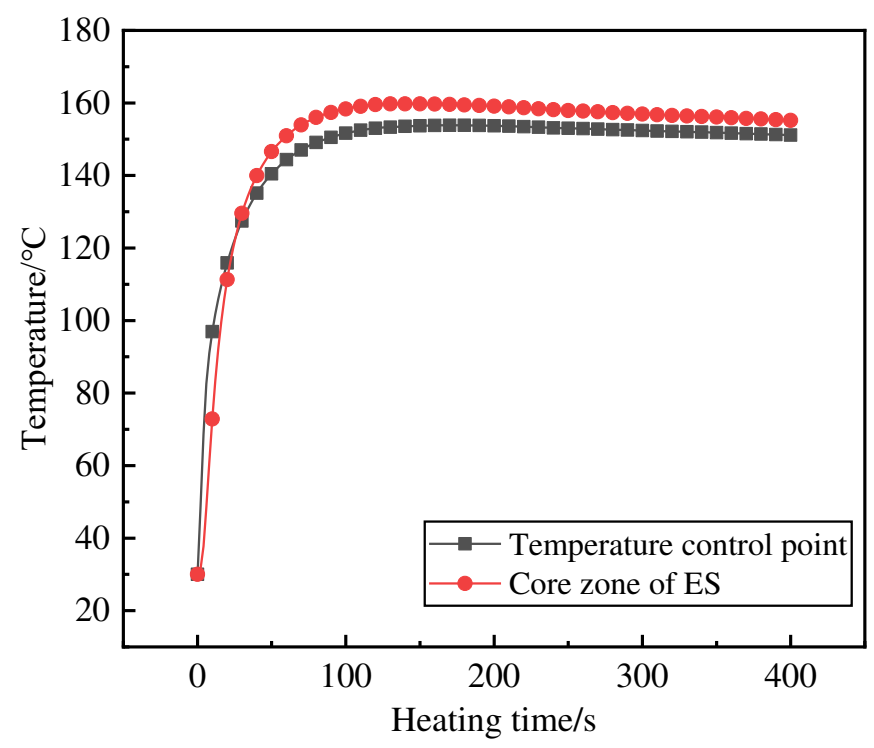

Fig. 6. Temperature variation in the core zone of the ES and the temperature control point

\subsection{Model verification}

In this paper, a roll profile electromagnetic control experimental platform is modified to measure circumferential bulging at different centre angles, as shown in Fig. 7. According to Formula 1, the radial bulging amount of the ECR can be calculated by the strain value of the foil gauge and the original length of the foil gauge:

$\Delta R=\frac{l+\varepsilon l}{\theta+\Delta \theta} \cdot R$

where $\Delta R$ is the radial bulging amount of the ECR, $R$ is the original radius of the ECR, $l$ is the original length of the foil gauge, $\varepsilon$ is the strain value of the foil gauge, $\theta$ is the angle of the centre of the circle corresponding to the length of the foil gauge and $\Delta \theta$ is the angle variation of the centre of the circle. Compared with the value of $\theta$, the value of $\Delta \theta$ is small and can be ignored in Formula 1. 


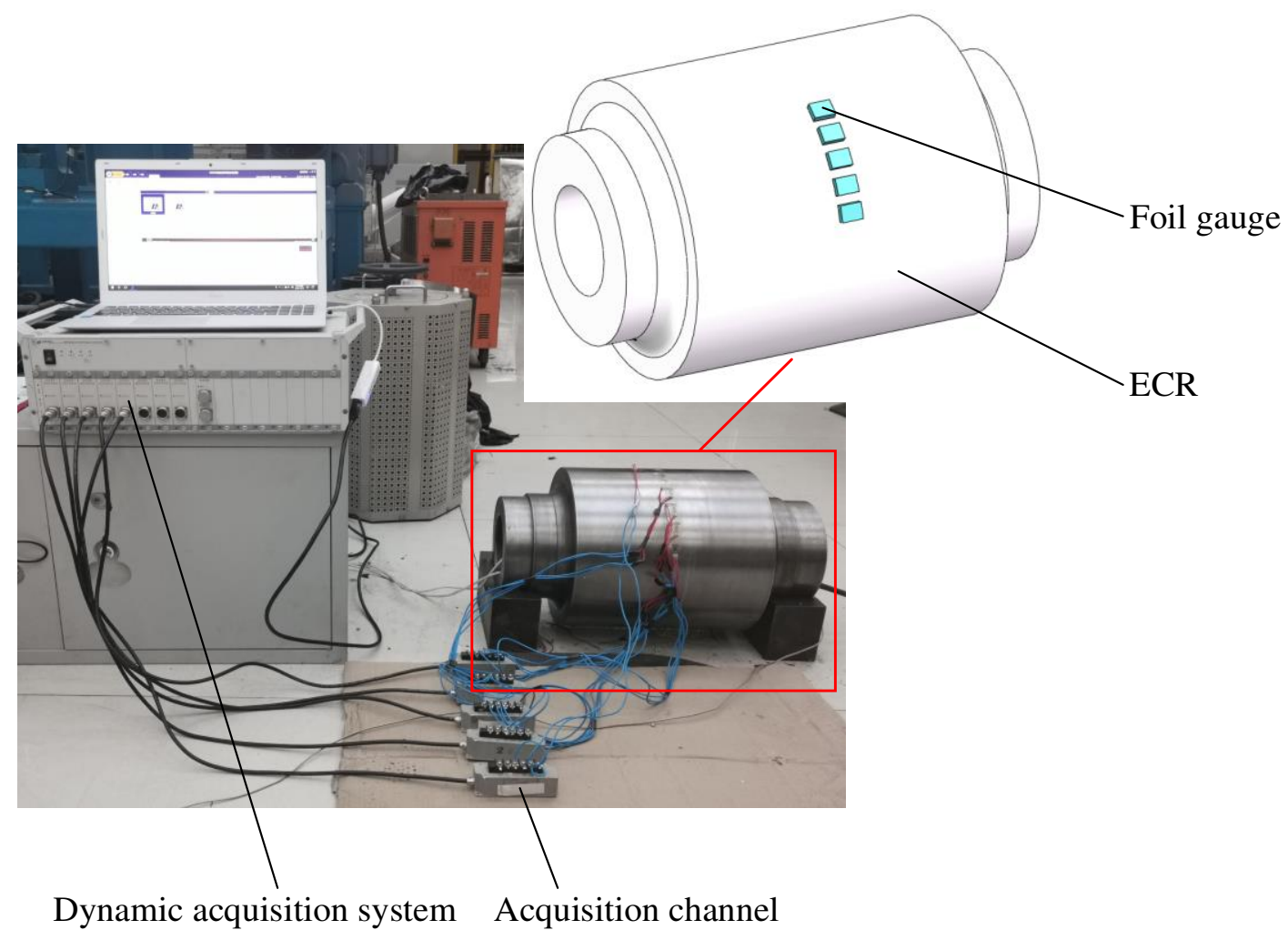

Fig. 7. The modified roll profile electromagnetic control experimental platform

The experimental conditions were as follows: the control frequency is $400 \mathrm{~Hz}$, the control current is $90 \mathrm{~A}$, the ambient temperature is $17^{\circ} \mathrm{C}$, the maximum temperature of the temperature control point is $130{ }^{\circ} \mathrm{C}$, the structure of ES is the segmented electromagnetic stick, and the cooling intensity of the roll surface is $0 \mathrm{~kW} /\left(\mathrm{m}^{2} \cdot \mathrm{K}\right)$. Fig. 8 is the average radial bulging profile in experiment and simulation. In the first stage of Fig. 8, the difference between the experimental results and the simulation results can be seen. The reason is that the contact between the inner hole of ECR and the ES is insufficient in this stage, and the phenomenon of magnetic flux leakage appears, leading that the actual effect is lower than the simulated effect. With the control of roll profile, the ES bulges and contacts closely with ECR, the magnetic flux leakage phenomenon disappears, and the regulation effect gradually achieves the expected effect.

As a whole, the experimental results and the simulation results show a higher degree of consistency, and the deviation is small. Therefore, the FE model of circumferential of RPECT can be used for researching the problem of RPECT, and the results are credible. 


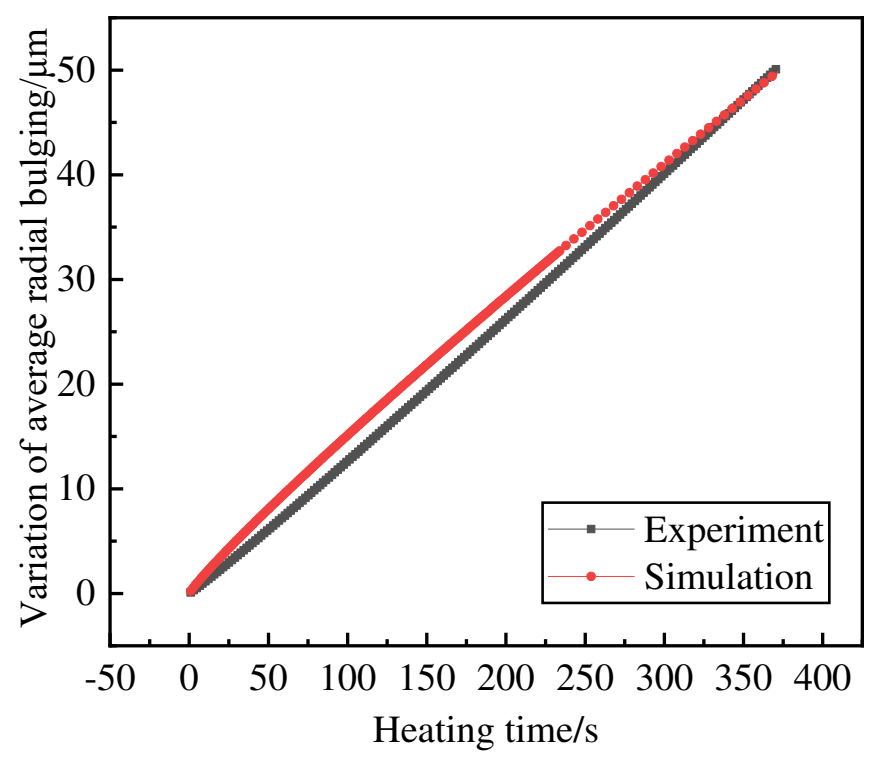

Fig. 8. The variation of average radial bulging in experiment and simulation

\section{Results and Discussion}

\subsection{The influence of the roll radius}

To study the influence of the roll radius on the roll profile control ability, the roundness and variation of the radial bulging of the ECR under different roll radii are shown in Fig. 9. In the control process, the roll profile can gradually achieve the control goal as the thermal and force complex mechanism reaches a stable status. Therefore, research on the roll profile control ability needs to be carried out at the stable status of RPECT. In this paper, the stable status of all the cases is $300 \mathrm{~s}$, and the graphic data are collected at the stable status. The result of Fig. 9 (a) shows that the variation in the roundness can be considered as two stages. In the first stage, the roundness decreases gradually with increasing roll radius, and the relationship between the roundness and roll radius can be considered an approximately linear correlation. In the second stage, when the roll radius exceeds $170 \mathrm{~mm}$, the roundness does not decrease and gradually stabilizes at $0.04 \mu \mathrm{m}$. Different from the variation in roundness, the radial bulging value continues to decrease as the roll radius increases, as shown in Fig. 9 (b). It should be noted that there is a platform of radial deformation in the roll radius range of $100 \mathrm{~mm}$ to $140 \mathrm{~mm}$, and the radial bulging value does not decrease with the increase of the roll radius in this platform. 

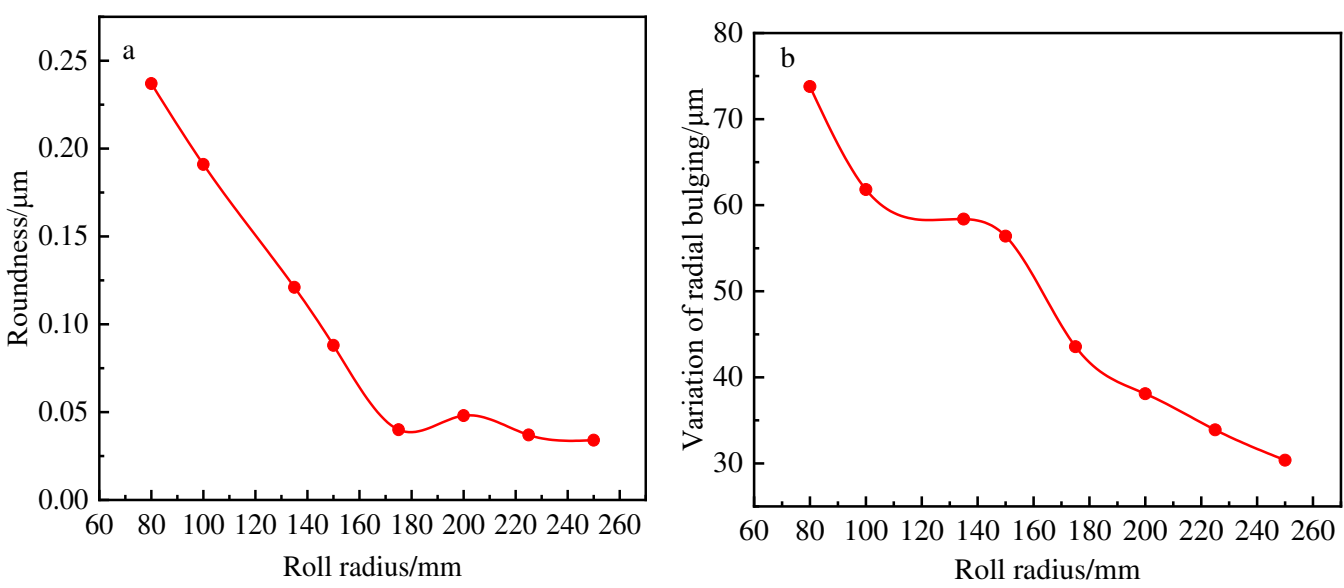

Fig. 9. Status of ECR bulging under different roll radii: (a) roundness and (b) variation in radial bulging.

Considering that the roll profile of RPECT is composed of a force contribution of the roll profile and a thermal contribution of the roll profile, further analysis of the stress field and the temperature field is needed for a causal analysis of this radial bulging platform. Fig. 10 shows the stable stress status of the ECR with different roll radii. The result shows that the circumferential distribution of stress is asymmetric when the roll radius is small. In Fig. 10, the circumferential uniformity of stress in the case with a $100-\mathrm{mm}$ roll radius is the worst, and its stress field can be described as a quadrilateral distribution corresponding to four slots of the ES. When the roll radius is increased to $135 \mathrm{~mm}$, the maximum stress of the roll surface among the cases appears, and the difference in stress between the roll surface and the roll inner hole wall is much smaller than those in the other cases. Meanwhile, the circumferential uniformity of stress is obviously improved compared with Fig. 10 (a). In Fig. 10 (c), the stress of the roll surface decreases, but the circumferential uniformity of the stress increases. In the control process, the stress field near the roll inner hole has a quadrilateral distribution and that far away from the hole has a circular distribution. With increasing roll radius, the scale of the quadrilateral distribution area decreases, while that of the circular distribution area increases. Meanwhile, the variation of the roll radius can lead to the different variation of stress between the roll surface and the roll inner hole wall, resulting in the change in the thermal and force complex mechanism. 


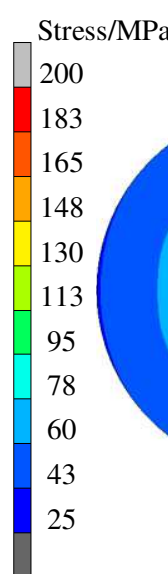
(c) $150 \mathrm{~mm}$.

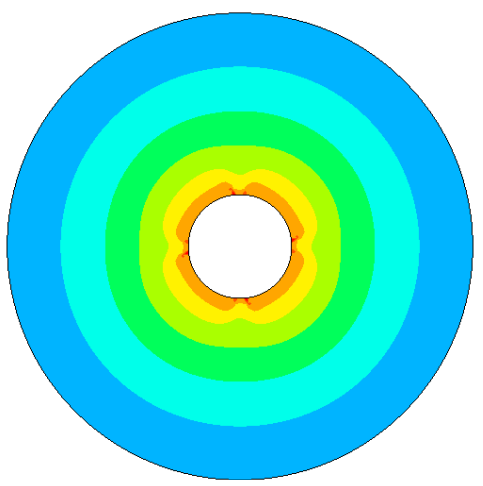

(b)

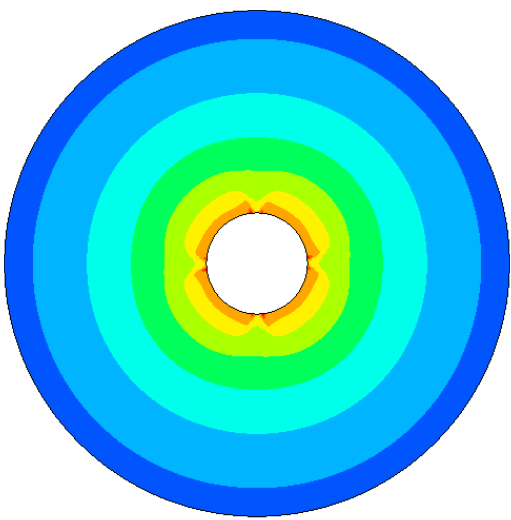

(c)

(a)

Fig. 10. Stress field of the ECR with different roll radii: (a) $100 \mathrm{~mm}$; (b) $135 \mathrm{~mm}$; and

Fig. 11 shows the temperature field of the ECR with different roll radii from 100 $\mathrm{mm}$ to $150 \mathrm{~mm}$. The result shows that the increase in the roll radius has a nonlinear influence on the temperature distribution of the ECR. Compared with Fig. 11 (a) and Fig. 11 (b), the roll surface temperature of the ECR with a $100-\mathrm{mm}$ roll radius is $62{ }^{\circ} \mathrm{C}$, while that of the ECR with a $135-\mathrm{mm}$ roll radius is $38^{\circ} \mathrm{C}$. Due to the increase in the roll radius, the distance between the heat source and the roll surface decreases, which results in a decrease in the roll surface temperature. Compared with Fig. 11 (b) and Fig. 11 (c), when the roll radius increases to $135 \mathrm{~mm}$, the roll surface temperatures of the ECR have little difference in different cases, and the scale of the temperature field of the ECR is decreased.

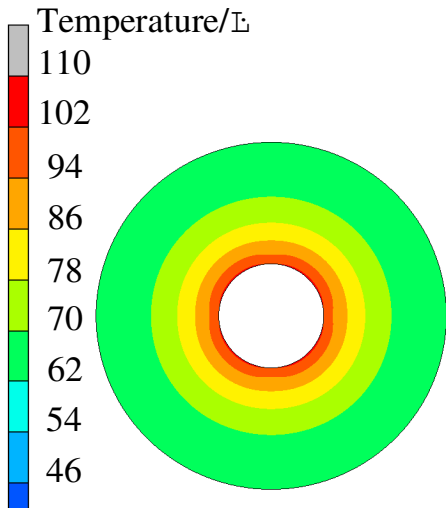

(a)

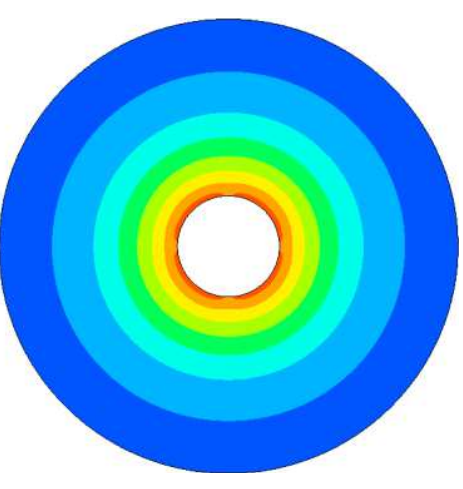

(b)

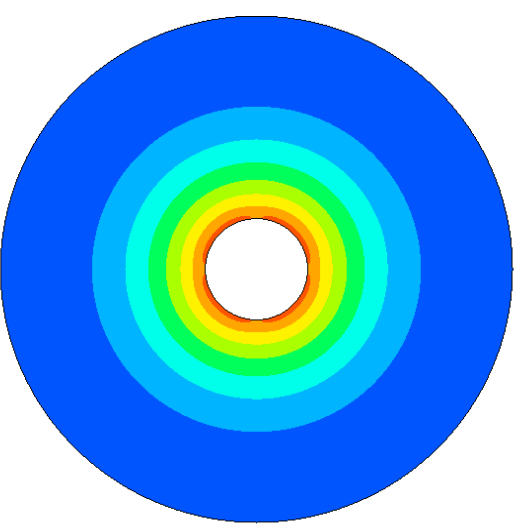

(c)

Fig. 11. Temperature field of ECR with different roll radii: (a) $100 \mathrm{~mm}$; (b) $135 \mathrm{~mm}$; and (c) $150 \mathrm{~mm}$. 
To analyse the roll profile control ability, it is necessary to further analyse the variation of the force crown and thermal crown under the influence of the roll radius. The force crown and the thermal crown under the stable status of RPECT are shown in Fig. 12. When the roll radius range is from $100 \mathrm{~mm}$ to $135 \mathrm{~mm}$, the difference in the thermal crown is small, and the force crown decreases with increasing roll radius. When the roll radius is more than $135 \mathrm{~mm}$ and less than $150 \mathrm{~mm}$, the thermal crown is decreased, and the force crown is increased with increasing roll radius. Combined with the results of Fig. 9 (b), when the roll radius is greater than $100 \mathrm{~mm}$ and less than 150 $\mathrm{mm}$, the change in the thermal crown is basically equal to that of the force crown, leading to mutual compensation between the thermal crown and force crown. The dynamic compensation makes the comprehensive crown change little at this time, and the curve has a plateau stage.

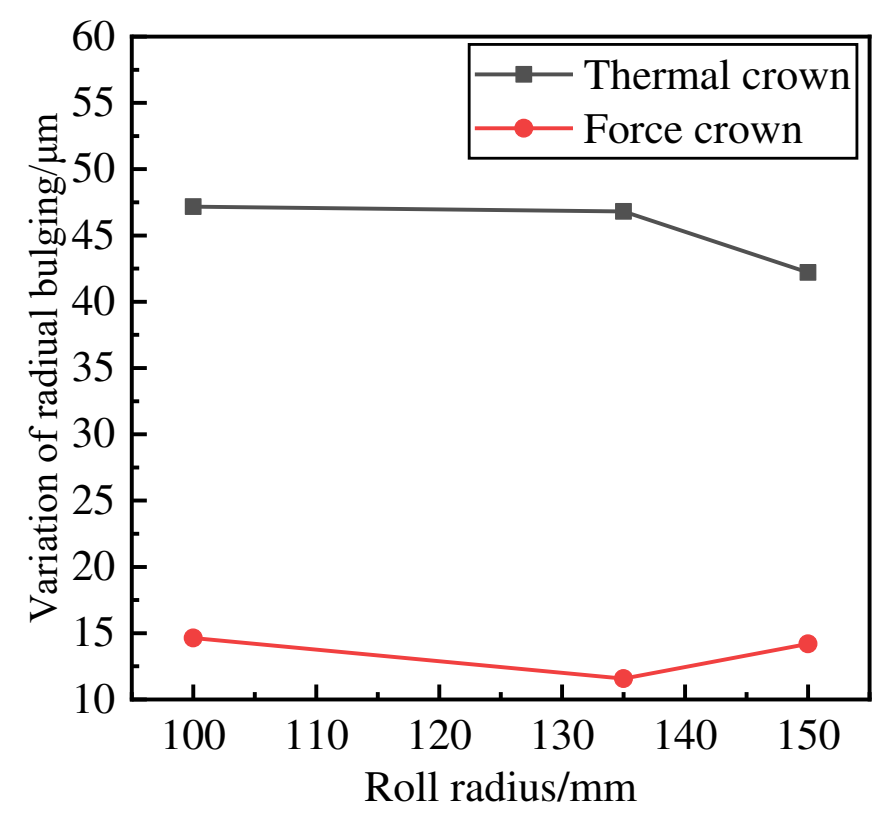

Fig. 12. Thermal crown variation and force crown variation under different roll radii

According to the above results, when the range of the roll radius is from $100 \mathrm{~mm}$ to $150 \mathrm{~mm}$, the root cause of the dynamic compensation is that the effect of the temperature field and stress field of the ECR on the roll profile is in dynamic equilibrium. The stress variation of the ECR is mainly affected by the thermal expansion mechanism of the ES and the internal restraint mechanism of the ECR, while the two mechanisms are affected by the temperature fields of the ES and ECR. The 
results of Fig. 10 (a) and Fig. 11 (a) show that when the roll radius is small, the distance between the heat source of the ES and the ECR surface is shortened, the heat transfer from the roll inner hole to the roll surface is increased, the temperature difference between the ECR surface and the inner hole is small, the internal restraint mechanism of RPECT is weakened due to the small roll radius, and the force crown is reduced. The results of Fig. 10 (b) and Fig. 11 (b) show that the temperature difference between the inside and outside of the ECR is higher than that of the previous cases, but the internal constraint mechanism is still weak. At the same time, affected by the increase in the roll radius, the force bulging ability of the ECR is weakened, and the force crown is smaller than that of the previous working cases. The results of Fig. 10 (c) and Fig. 11 (c) show that the internal and external temperature difference of the ECR is larger than that of the first two cases, the high temperature region is distributed near the roll inner hole, and the internal restraint mechanism is stronger than that of the first two cases. At this time, the force crown is still affected by the increase in the roll radius, but overall, the force crown increases. In addition, because the high-temperature region is smaller than the first two cases, the thermal crown is also decreased. As the above series of thermal crowns and force crowns changes, the change in the comprehensive crown is small, and the curve is relatively stable in this section.

\subsection{The influence of the slot radius}

To analyse the influence of the slot radius on the roll profile control ability, the roundness of the ECR and the variation in radial bulging under different slot radii are shown in Fig. 13. With increasing slot radius, the difference between the maximum bulging value and the minimum bulging value can be increased, and the variation in radial bulging can be decreased. When the slot radius is increased from $2.5 \mathrm{~mm}$ to 7.5 $\mathrm{mm}$, the maximum roundness is $0.291 \mu \mathrm{m}$, and the corresponding roll bulging value is $46.76 \mu \mathrm{m}$. Meanwhile, the minimum roundness is $0.076 \mu \mathrm{m}$, and the corresponding roll bulging value is $59.29 \mu \mathrm{m}$. The roll profile control ability and the circumferential uniformity can be significantly weakened when the slot radius increases. In this process, the slot with the larger radius can provide more installation space for the induction coil, 
295 indirectly improve the selection range of the coil cross-sectional area and expand the 296 adjustable range of current.
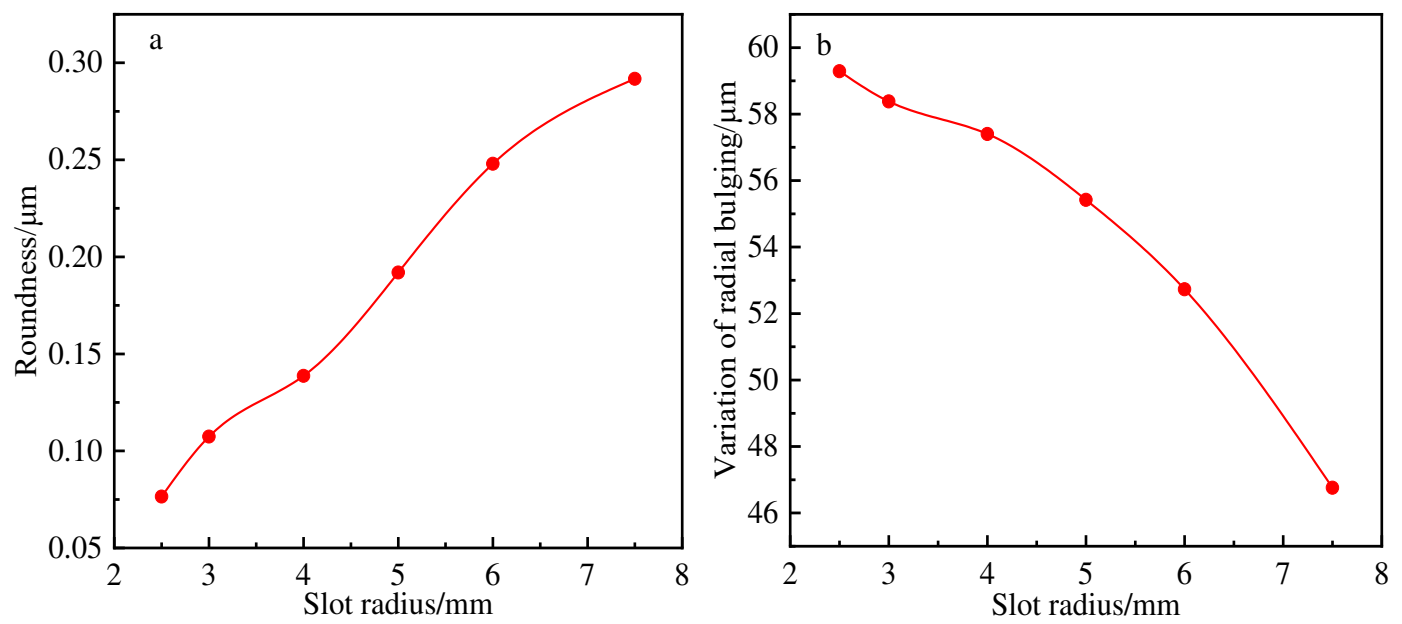

Fig. 13. Status of ECR bulging under different slot radii: (a) roundness and (b) variation in radial bulging.

To further analyse the reason for the variation in radial bulging, the internal stress fields of the ECR under different slot radii are extracted, as shown in Fig. 14. With increasing slot radius, the scale of the stress field of the ECR can be continuously decreased, the maximum stress value decreases, and the stress field near the roll inner hole begins to show a quadrilateral distribution. The cause of this phenomenon is that the contact area of the ES can be reduced while the slot is expanded, and the distribution of contact pressure between the ES and ECR begins to exhibit the cam effect. The larger the hole radius is, the more obvious the cam effect is. Even when the slot radius is 7.5 $\mathrm{mm}$, the internal stress field of the ECR shows a symmetrical stress field controlled by four bulging regions, and the asymmetry of the stress field is intensified. 


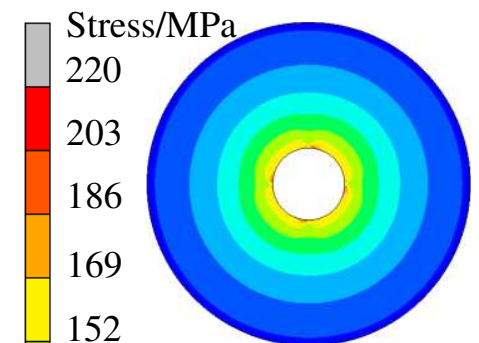

(a)

135

118

101

84

67

50

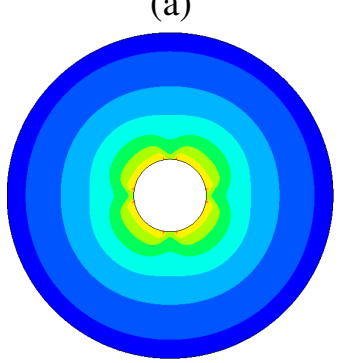

(c)

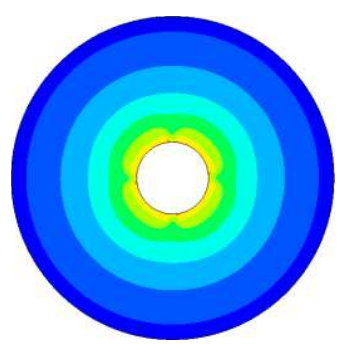

(b)

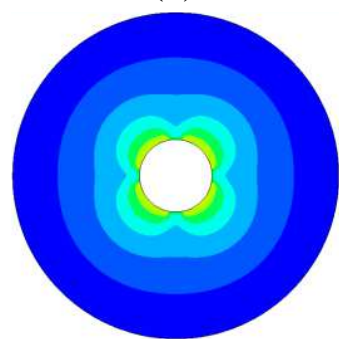

(d)

311 Fig. 14. Stress status of the ECR under different slot radii: (a) slot radius of $2.5 \mathrm{~mm}$, (b) slot radius of $3 \mathrm{~mm}$, (c) slot radius of $5 \mathrm{~mm}$, and (d) slot radius of $7.5 \mathrm{~mm}$.

Fig. 15 shows the temperature field of the ECR under different slot radii. The temperature field of the ECR also has characteristics of circumferential nonuniform distribution. Compared with the stress field, the sensitivity of the slot radius to the temperature field is weaker. The reason for this phenomenon lies in the difference between the thermal contribution roll profile and the force contribution roll profile in the RPECT. The heat can be transferred in the circumferential direction, but the contact pressure can only act on the contact surface between the ES and ECR. When the slot radius is small, the circumferential transmission of heat is not affected by the slot, and the temperature field cannot be affected by the slot structure of the ES, as shown in Fig. 15 (a) and Fig. 15 (b). However, when the slot radius is large enough, the space occupied by the slot can block the circumferential heat transfer around the ES, forming four thermally affected zones with right angle fan shapes, which leads to the difference in the internal constraint mechanism of RPECT, as shown in Fig. 15 (c) and Fig. 15 (d). 


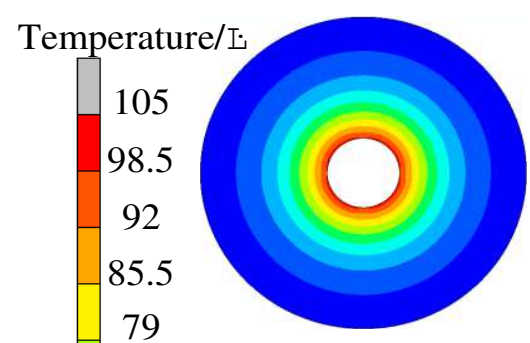

(a)

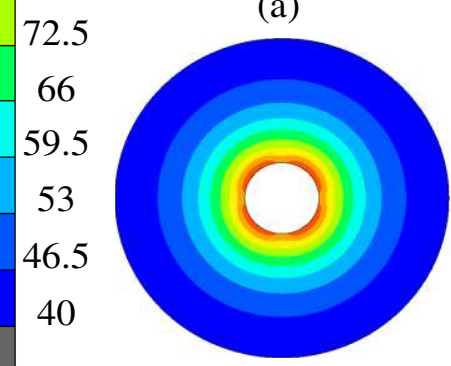

(c)

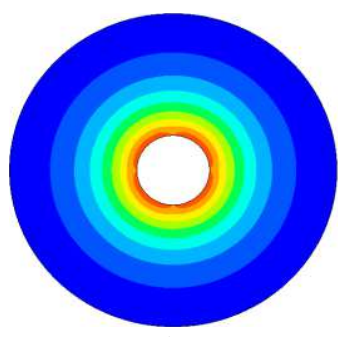

(b)

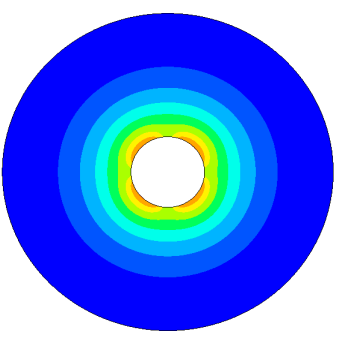

(d)

327 Fig. 15. Temperature field of the ECR under different slot radii: (a) slot radius of 2.5 $\mathrm{mm}$, (b) slot radius of $3 \mathrm{~mm}$, (c) slot radius of $5 \mathrm{~mm}$, and (d) slot radius of $7.5 \mathrm{~mm}$.

Fig. 16 shows the variation in the thermal crown and the variation in the force crown with the slot radius. With increasing slot radius, the force crown first increases and then decreases; the thermal crown first decreases, then tends to be stable and finally decreases. Combined with the previous analysis, when the slot radius is less than $4 \mathrm{~mm}$, increasing the slot radius can increase the proportion of the force crown in the comprehensive roll crown, and the comprehensive roll crown decreases less at this time. When the slot radius exceeds $4 \mathrm{~mm}$, increasing the slot radius is no longer the method of increasing the proportion of the force crown and can also cause a decline in the comprehensive roll crown. 


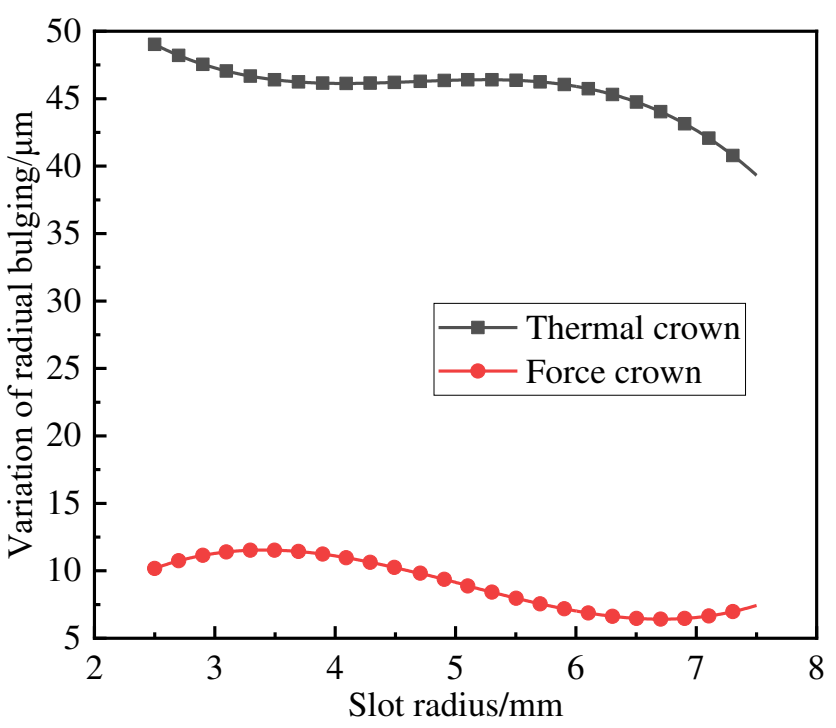

Fig. 16. Thermal crown variation and force crown variation under different slot radii In addition to the bulging ability, the stress distribution of the ES with different slot radii should be analysed due to the local structural change of the ES with the slots. The stress status of the ES under different slot radii is extracted, as shown in Fig. 17. The result shows that when the slot radius increases, the internal stress of the ES and the crush risk of the ES are increased. The high stress region appears around the slots and in the centre of the ES. When the slot radius is $2.5 \mathrm{~mm}, 3 \mathrm{~mm}$ and $5 \mathrm{~mm}$, the stress size and the stress field scale in the core of the ES are basically the same, and the stress field in the core can be regarded as a circular distribution; when the slot radius is $7 \mathrm{~mm}$, the high stress area of the ES can connect the core of the ES and the area around the slot and form the maximum stress around the slot. At this time, the roll profile control ability of the ES is decreased, and the roundness value is increased, which is not conducive to achieving the goal of roll profile control. 


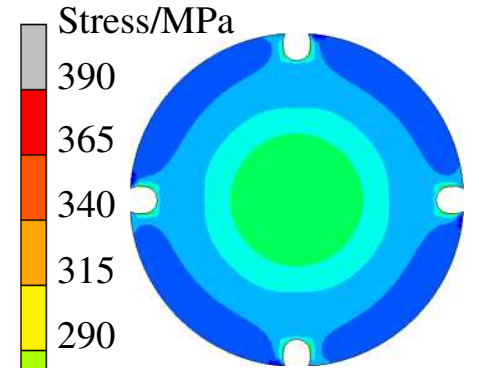

(a)

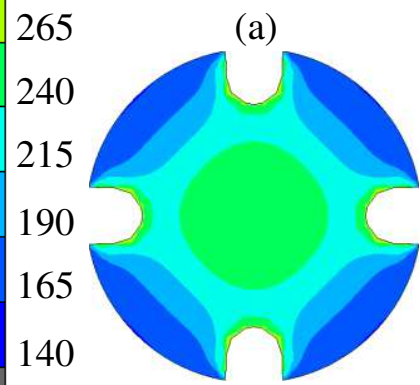

(c)

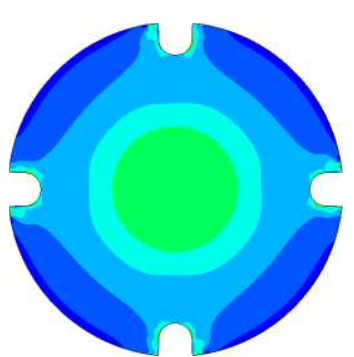

(b)

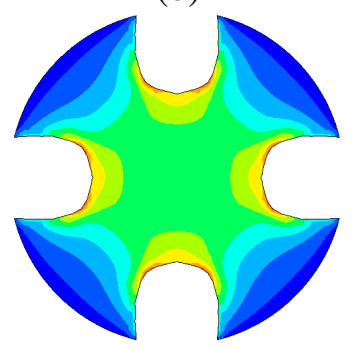

(d)

Fig. 17. Stress field of the ES under different slot radii: (a) slot radius of $2.5 \mathrm{~mm}$, (b) slot radius of $3 \mathrm{~mm}$, (c) slot radius of $5 \mathrm{~mm}$, and (d) slot radius of $7.5 \mathrm{~mm}$.

\subsection{The influence of the slot amount}

According to the above study, electromagnetic sticks with 2.5-mm, 3-mm and 5$\mathrm{mm}$ holes are selected to study the influence of the slot amount on the roll profile control ability. Fig. 18 shows the roundness of the ECR and the variation in radial bulging under different slot amounts. The roundness of the ECR and the variation in radial bulging can decrease with increasing slot amount, and the decreasing trend is more obvious when the hole radius is larger. This shows the improvement of circumferential uniformity and the decrease of the roll profile control ability after electromagnetic control roll bulging. When the slot amount is 4 , the regularity of the roundness and the radial bulging variation is the same as the previous analysis; when the slot amount increases, the roundness value of the ECR with a 3-mm hole is less than that of the ECR with a $2.5-\mathrm{mm}$ hole, and the reduction of the radial bulging value of the ECR with a 3 $\mathrm{mm}$ hole is less than that of the ECR with a 5-mm hole. Meanwhile, the results in Fig. 18 (b) show that the ECR with a 3-mm hole has a better radial bulging ability than the ECR with a 5-mm hole when the slot amount is arbitrary. Therefore, it can be considered to use the reasonable configuration strategy of the hole radius and slot 
amount to reduce the roundness of the ECR while ensuring that the roll has the control ability required by strip flatness control.
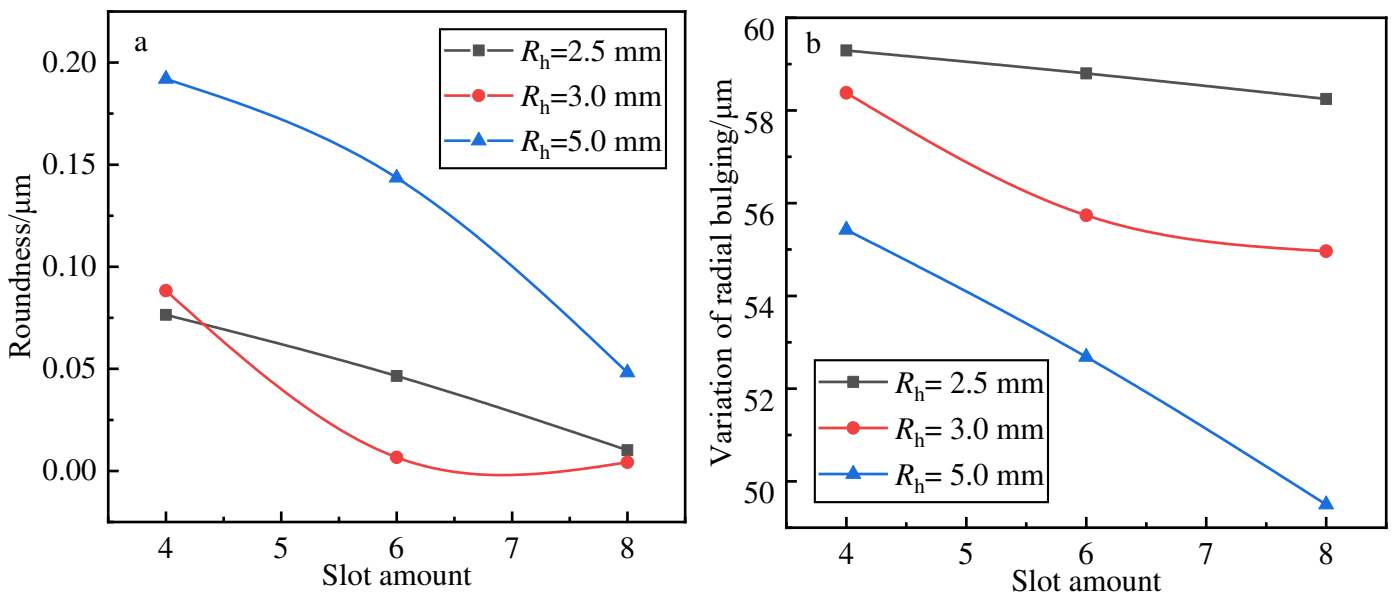

Fig. 18. Status of ECR bulging under different slot amounts: (a) roundness and (b) variation in radial bulging.

Fig. 19 shows the stress status of the ECR under different slot amounts and hole radii. With increasing slot amounts, the stress field around the roll inner hole can be described as a polygonal distribution. The side number of this polygonal corresponds to the slot amount. In addition, the heterogeneity of the stress distribution can be enhanced with increasing hole radius, which increases the heterogeneity of the force contribution of the roll profile. When the slot amount and hole radius are large, a large stress can be formed in the contact position between the inner hole of the ECR and the surface of the ES, and the stress field far away from the inner hole of the ECR also presents a polygonal distribution trend. 

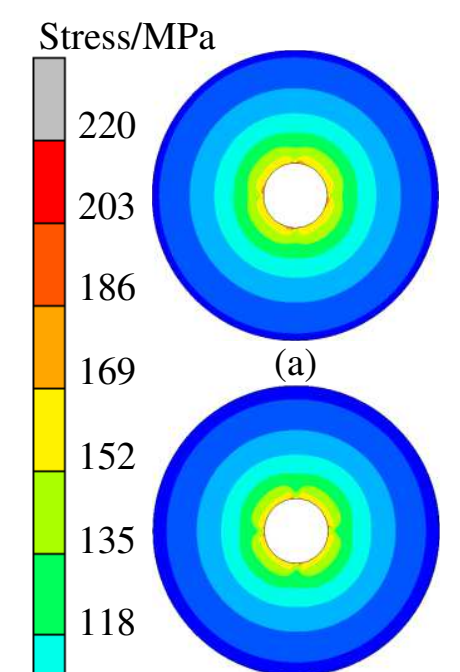

101
84
67
50 (d)

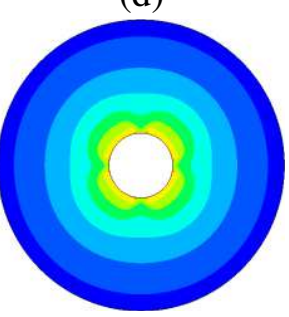

(g)

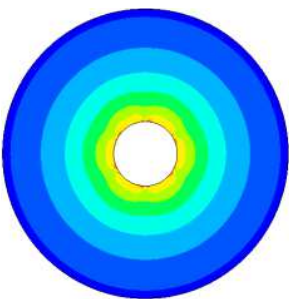

(b)

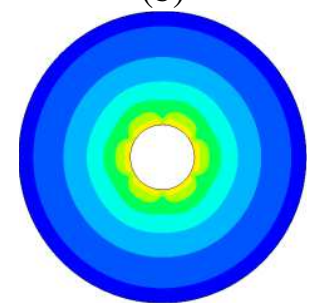

(e)

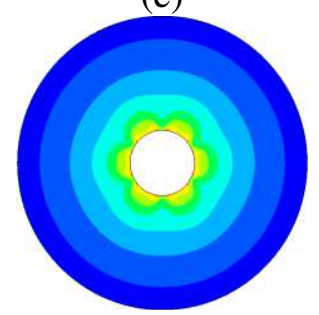

(h)

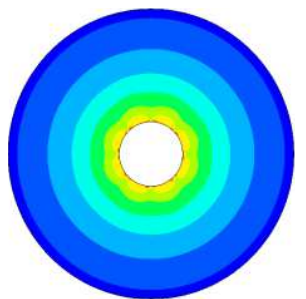

(c)

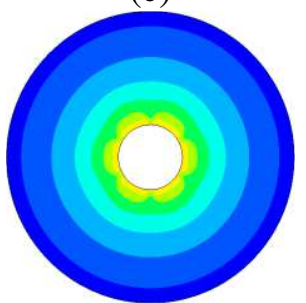

(f)

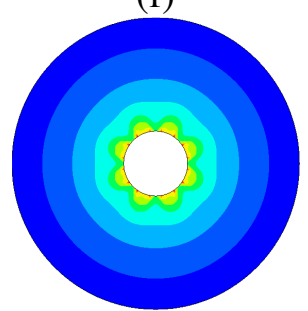

(i)

Fig. 19. Stress status of the ECR under different slot amounts: (a) $R_{\mathrm{h}}=2.5 \mathrm{~mm}, N=4$, (b) $R_{\mathrm{h}}=2.5 \mathrm{~mm}, N=6$, (c) $R_{\mathrm{h}}=2.5 \mathrm{~mm}, N=8$, (d) $R_{\mathrm{h}}=5 \mathrm{~mm}, N=4$, (e) $R_{\mathrm{h}}=5 \mathrm{~mm}, N=6$, (f) $R_{\mathrm{h}}=5$ $\mathrm{mm}, N=8$, (g) $R_{\mathrm{h}}=7.5 \mathrm{~mm}, N=4$, (h) $R_{\mathrm{h}}=7.5 \mathrm{~mm}, N=6$, and (i) $R_{\mathrm{h}}=7.5 \mathrm{~mm}, N=8$.

Fig. 20 shows the temperature field of the ECR under different slot amounts and hole radii. The temperature field around the roll inner hole is also affected by the space occupied by the hole, which shows a polygonal distribution trend, and the side number of the polygonal is the same as the slot amount. When the hole radius is $2.5 \mathrm{~mm}$, the slot amount has little influence on the temperature distribution around the roll inner hole. The reason is that the smaller hole cannot block the circumferential heat transfer between the ES and ECR, and the temperature field can still be homogenized on the inner hole wall. With increasing hole radius, the hole size is large enough to block circumferential heat transfer on the inner hole wall, and the temperature field around the roll inner hole begins to show a nonuniform distribution. When the hole radius is 5 $\mathrm{mm}$, the ECR temperature field under various slot amounts presents a nonuniform phenomenon, and the temperature near the inner hole is far less than that in the other working cases; therefore, the thermal expansion ability and the internal restraint ability 
are greatly reduced.
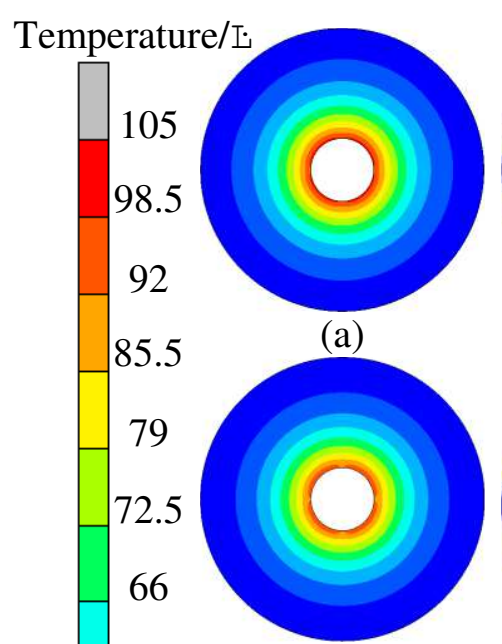

59.5 53
46.5
40 (d)

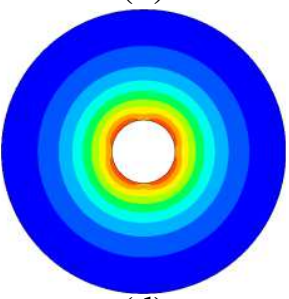

(d)

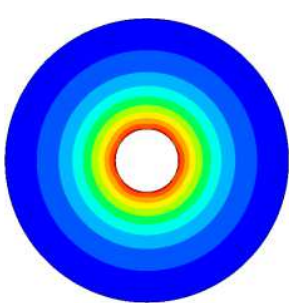

(b)

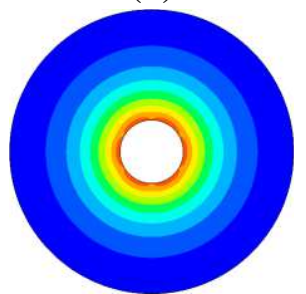

(e)

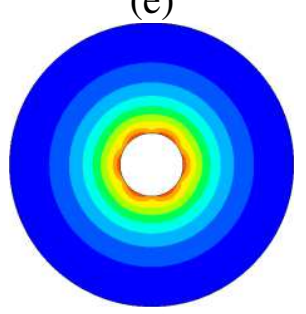

(e)

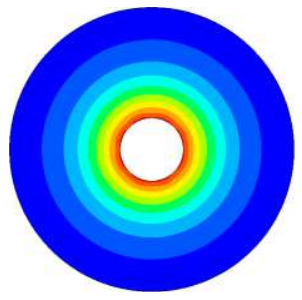

(c)

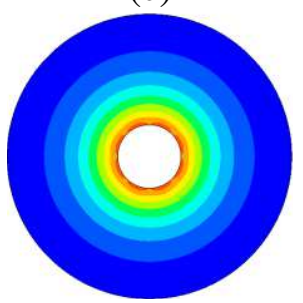

(f)

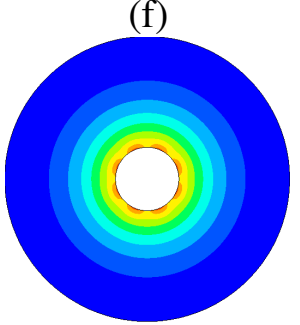

(f)

Fig. 20. Temperature field of the ECR under different slot amounts: (a) $R_{\mathrm{h}}=2.5 \mathrm{~mm}$, $N=4$, (b) $R_{\mathrm{h}}=2.5 \mathrm{~mm}, N=6$, (c) $R_{\mathrm{h}}=2.5 \mathrm{~mm}, N=8$, (d) $R_{\mathrm{h}}=5 \mathrm{~mm}, N=4$, (e) $R_{\mathrm{h}}=5 \mathrm{~mm}, N=6$, (f) $R_{\mathrm{h}}=5 \mathrm{~mm}, N=8$, (g) $R_{\mathrm{h}}=7.5 \mathrm{~mm}, N=4$, (h) $R_{\mathrm{h}}=7.5 \mathrm{~mm}, N=6$, and (i) $R_{\mathrm{h}}=7.5 \mathrm{~mm}, N=8$.

To further analyse the influence of the changes in the stress field and temperature field on the roll profile control ability, the thermal crown and force crown under different cases are extracted, as shown in Fig. 21. The result of Fig. 21 (a) shows that the thermal crown can be decreased by increasing the hole radius and the slot amount. According to the result of Fig. 20, with the increase in the hole radius or slot amount, the temperature field of the ECR is weakened, and the thermal bulging ability of the ECR can be decreased. It is noteworthy that when the hole radius is larger, the decrease in the thermal crown is larger with an increasing slot amount. In the case of a large hole radius and a large slot amount, the heat transfer area between the ES and ECR is greatly reduced by the influence of holes, resulting in the weakening of heat transfer between the ES and ECR, the decrease of heat storage in the ECR and the decrease of the thermal expansion ability. 
The result of Fig. 21 (b) shows that the entire trend of force crown variation is a

slight increase at first and then a decrease with an increase in the slot amount. Therefore, the change in the force crown can be regarded as two stages. In the first stage, when the hole radius or the slot amount increases, the contact area between the ES and ECR is decreased, and the temperature of the ES can be increased, resulting in an increase in the ES bulging ability and an improvement in the force crown. In the second stage, although the bulging ability of the ES is enhanced, the internal restraint ability of the ECR is weakened due to the influence of the temperature field, which reduces the contact stress between the electromagnetic bar, roll and force crown.
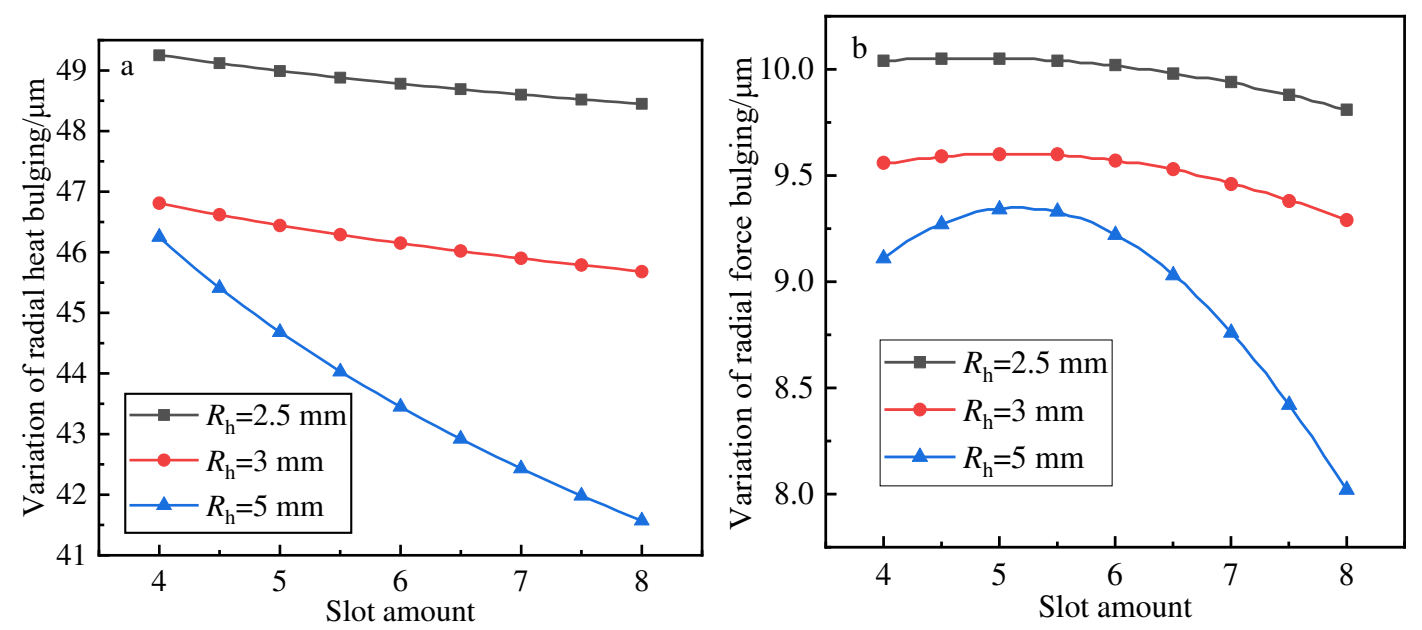

Fig. 21. Thermal crown variation and force crown variation under different slot amounts: (a) thermal crown and (b) force crown.

\section{Conclusion}

In this paper, for the hole structure and slot structure, the radial bulging ability, the roundness of bulging, and the composition between the thermal crown and the force crown under different holes or slots are discussed. The conclusions obtained are as follows:

(1) The radial bulging ability and the roundness under the influence of the roll radius are larger than those under the influences of the slot radius and slot amount, and the least influential factor is the slot amount. Due to the difference of heat-force hybrid driving in different conditions, the comprehensive crowns 
composed of the thermal crown and the force crown are different.

(2) In the ECR with the same inner hole and different roll radii, an increase in the roll radius can decrease the roll profile control ability, while the roundness can be maintained well. In this process of a roll radius increase, a platform of radius deformation is obtained by the dynamic equilibrium of the temperature field and stress field, and the existence of a variation curve of radial bulging needs to be considered in the process of ECR selection. On the premise of ensuring the roll profile control ability and the demand of the mill roll system, a smaller roll radius can be selected.

(3) The slot radius and the slot amount can determine the coil current load and the number of segments of the ES. Increasing the slot radius and slot amount can decrease the radial bulging value of the ECR, and the roundness can be maintained below $0.3 \mu \mathrm{m}$. The ES with a $3-\mathrm{mm}$ slot radius and 8 slots has good comprehensive crown control ability and roundness, which can be used for different rolling conditions.

\section{Author contributions}

The analysis of roundness, temperature field, stress field, roll profile control ability were done by Tingsong Yang; FE model establishment and FE model Validation were carried out by Jiayang Liu and Haonan Zhou; Experimental platform was built by Jiayang Liu and Zhiqiang Xu with the support of Fengshan Du; Tingsong Yang revised the paper. All authors have read and agreed to the published.

\section{Funding}

This work was supported by the National Natural Science Foundation of China (Grant No. U1560206 and Grant No. 51374184) for the support to this research.

\section{Data availability}

The data sets supporting the results of this article are included within the article and its additional files.

\section{Compliance with ethical standards}

Ethical approval Not applicable. 
Consent to participate

Consent to publish

Competing interests
The authors consent to participate.

The authors consent to publish.

The authors declare that they have no competing interests.

\section{References}

[1] YF Feng, WW Liu, TS Yang, FS Du, JN Sun, 2019. A flexible electromagnetic control technique for interference adjustment in large-size sleeved backup rolls. Metallurgical Research and Technology, 116(4):405. https://doi.org/10.1051/metal/2018122.

[2] WW Liu, YF Feng, TS Yang, FS Du, JN Sun, 2018. Analysis of the induction heating efficiency and thermal energy conversion ability under different electromagnetic stick structures in the RPECT. Applied Thermal Engineering, 145:277-286.

https://doi.org/10.1016/j.applthermaleng.2018.09.043.

[3] WW Liu, YF Feng, TS Yang, FS Du, JN Sun, 2019. Research on flexible roll profile electromagnetic control technology in precision rolling mill. Metallurgical Research \& Technology, 116(1):101. https://doi.org/10.1051/metal/2018013.

[4] WW Liu, YF Feng, TS Yang, FS Du, JN Sun, 2018. Theoretical and experimental research on the law of flexible roll profile electromagnetic control. Journal of Materials Processing Technology, 262:308-318. https://doi.org/10.1016/j.jmatprotec.2018.07.006.

[5] HJ Wang, WW Liu, TS Yang, YF Feng, FS Du, ZQ Xu, 2019. Analysis of influence of roller heterogeneity on roll profile electromagnetic control technology, Iron \& Steel, 54(10):45-51. https://doi.org/10.13228/j.boyuan.issn0449-749x.20180505.

[6] Lee Min Jung, Noh Dong Soon, Lee Eun Kyung, 2020. Characteristics of Largearea Porous Media Burner Applicable To Direct-fired Non-oxidizing Annealing Furnace. Applied Thermal Engineering, 186.

https://doi.org/10.1016/J.APPLTHERMALENG.2020.116489.

[7] HW Li, DW Zhang, F Han, H Guo, XF Ding, 2020. Experimental investigation on the effect of hole diameter on the leading edge region film cooling of a twist turbine blade under rotation conditions. Applied Thermal Engineering, 184.

https://doi.org/10.1016/j.applthermaleng.2020.116386.

[8] Enke C, Jorge Bertoldo Júnior, Vlassov V, 2020. Transient response of an axially- 
500 grooved aluminum-ammonia heat pipe with the presence of non-condensable gas.

501 Applied Thermal Engineering, 183:116135.

502 https://doi.org/10.1016/j.applthermaleng.2020.116135.

503 [9] HW Dai, JH Zhang, YY Ren, NH Liu, JW Lin, 2021. Effect of cooling hole 504 configurations on combustion and heat transfer in an aero-engine combustor. Applied 505 Thermal Engineering, 182:115664.

506 https://doi.org/10.1016/J.APPLTHERMALENG.2020.115664.

507 [10] GY Xu, TB An, ZQ Yu, C Li, 2020. Numerical investigation on film cooling 508 characteristics of slot-sectional diffusion holes combined with an internal cross-flow 509 channel. Applied Thermal Engineering, 181:115953.

510 https://doi.org/10.1016/J.APPLTHERMALENG.2020.115953

511 [11] WW Liu, YF Feng, JN Sun, FS Du, 2018. Analysis of the thermal-mechanical 512 problem in the process of flexible roll profile electromagnetic control. International 513 Journal of Heat and Mass Transfer, 120:447-457.

514 https://doi.org/10.1016/j.ijheatmasstransfer.2017.12.050 
Figures

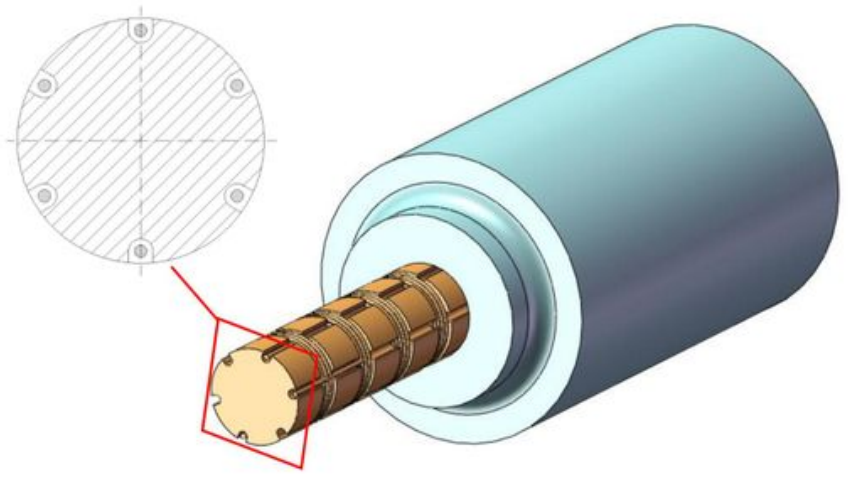

Fig. 1 The structure of the ES and the cross-section of the ES with induction coils

\section{Figure 1}

The structure of the ES and the cross-section of the ES with induction coils 


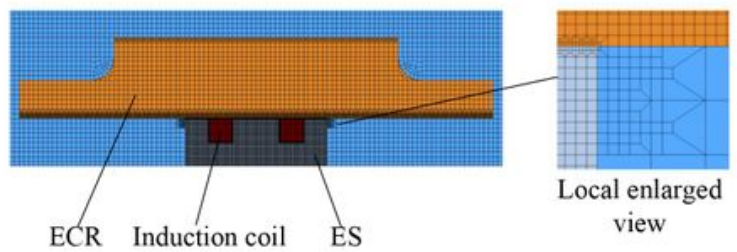

Fig. 2. The electromagnetic-thermal-mechanical coupled axisymmetric model of RPECT

Figure 2

The electromagnetic-thermal-mechanical coupled axisymmetric model of RPECT 


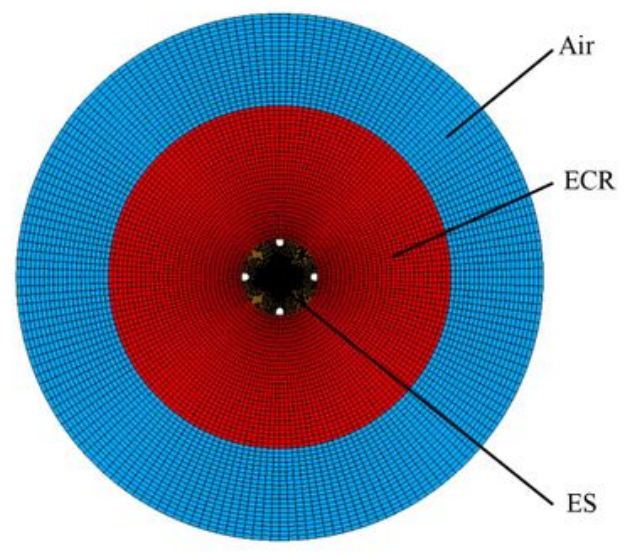

Fig. 3. The FE model of circumferential of RPECT

\section{Figure 3}

The FE model of circumferential of RPECT 


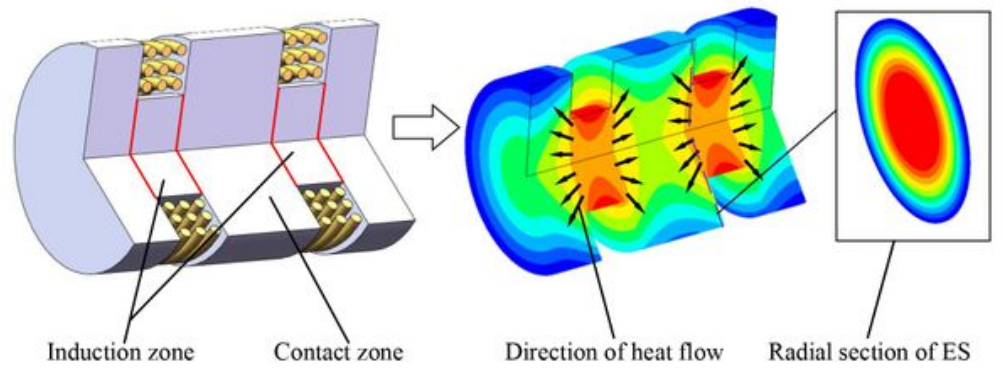

Fig. 4. The connection diagram of ES zones

\section{Figure 4}

The connection diagram of ES zones 


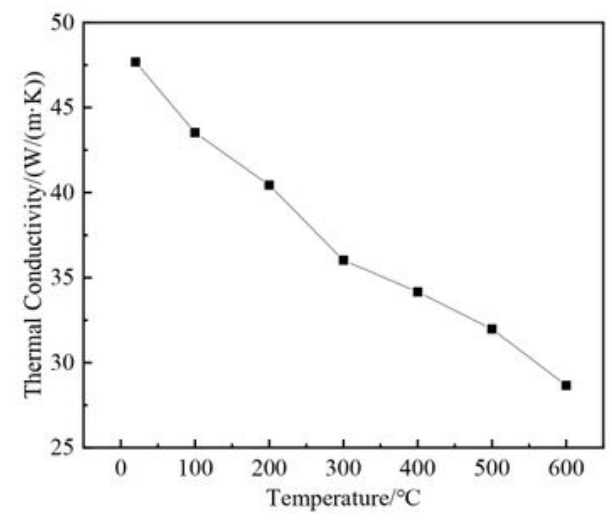

Fig. 5. The thermal properties of \#45 steel

Figure 5

The thermal properties of \#45 steel 


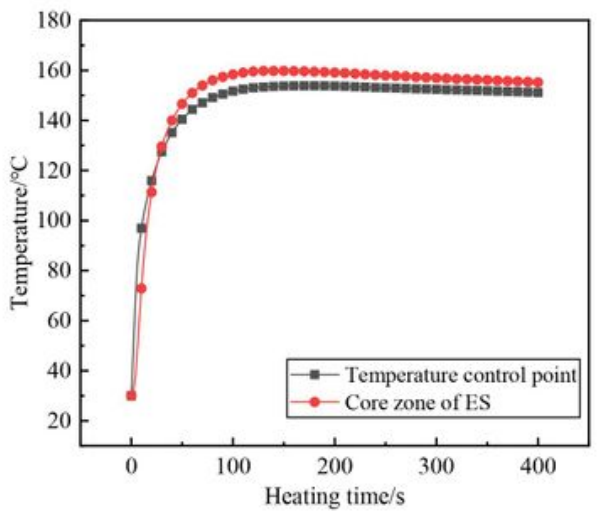

Fig. 6. Temperature variation in the core zone of the ES and the temperature control point

Figure 6

Temperature variation in the core zone of the ES and the temperature control point 


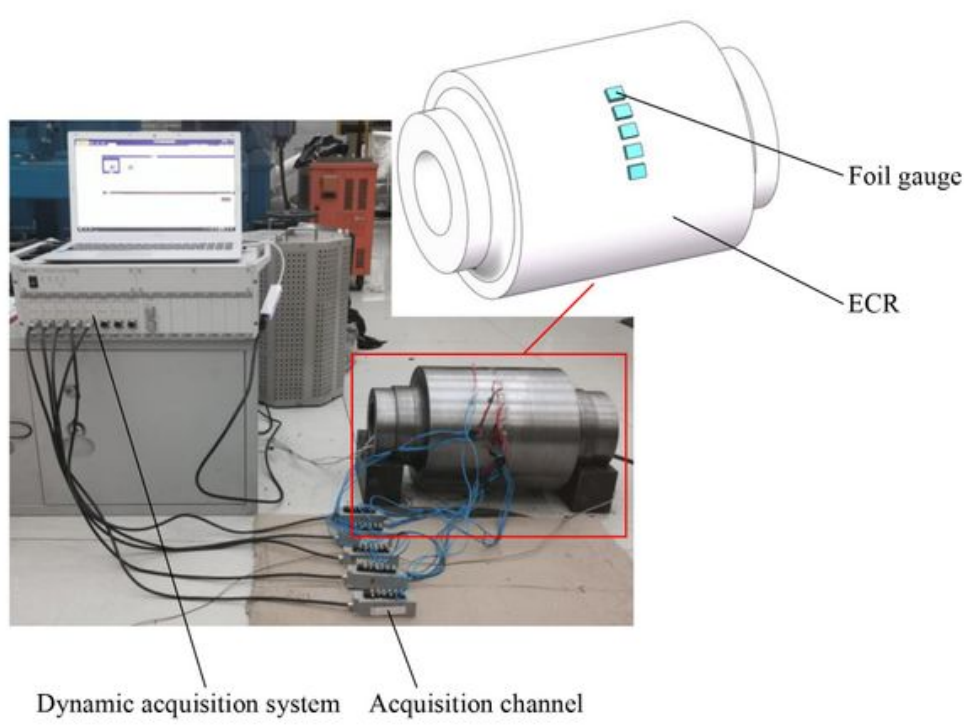

Fig. 7. The modified roll profile electromagnetic control experimental platform

Figure 7

The modified roll profile electromagnetic control experimental platform 


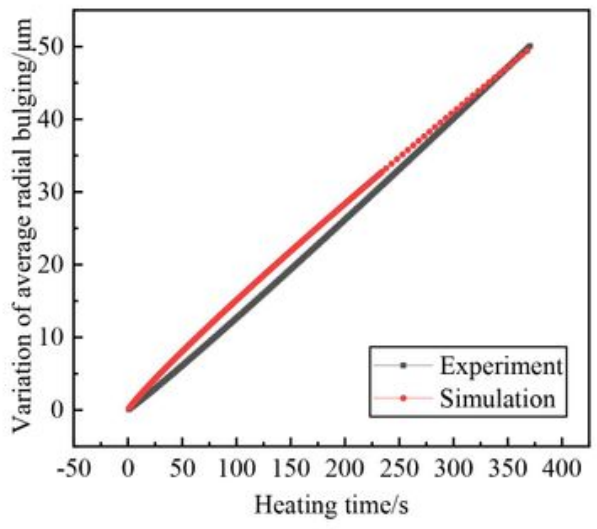

Fig. 8. The variation of average radial bulging in experiment and simulation

Figure 8

The variation of average radial bulging in experiment and simulation 

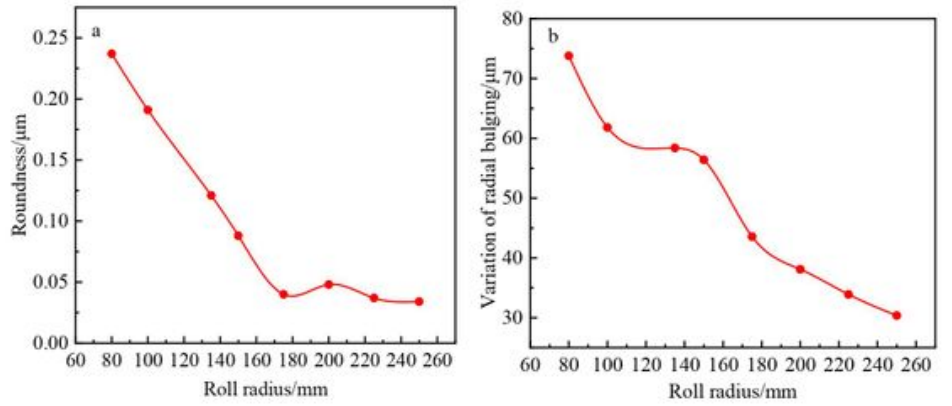

Fig. 9. Status of ECR bulging under different roll radii: (a) roundness and (b) variation in radial bulging.

Figure 9

Status of ECR bulging under different roll radii: (a) roundness and (b) variation in radial bulging. 


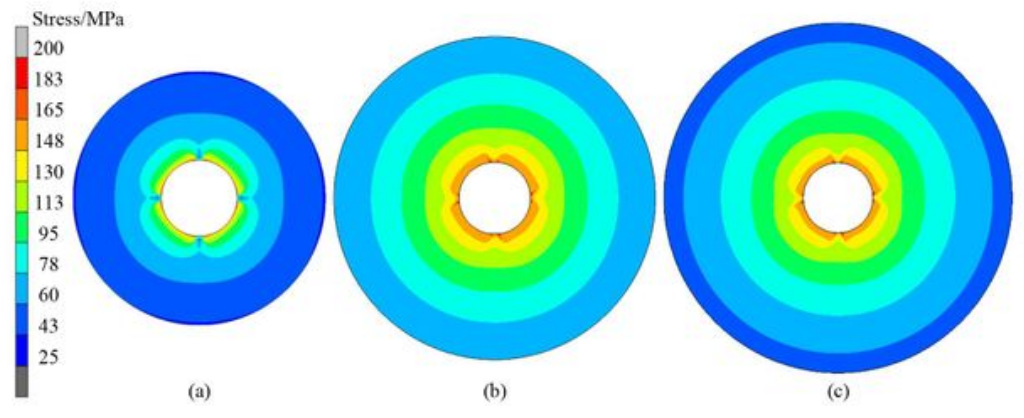

Fig. 10. Stress field of the ECR with different roll radii: (a) $100 \mathrm{~mm}$; (b) $135 \mathrm{~mm}$; and (c) $150 \mathrm{~mm}$.

Figure 10

Stress field of the ECR with different roll radii: (a) $100 \mathrm{~mm}$; (b) $135 \mathrm{~mm}$; and (c) $150 \mathrm{~mm}$. 


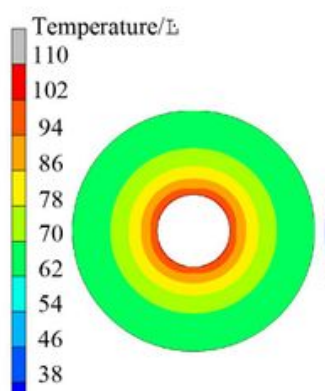

(a)

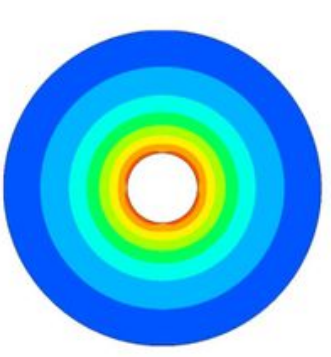

(b)

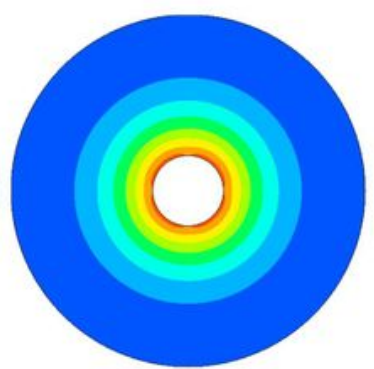

(c)

Fig. 11. Temperature field of ECR with different roll radii: (a) $100 \mathrm{~mm}$; (b) $135 \mathrm{~mm}$; and (c) $150 \mathrm{~mm}$.

Figure 11

Temperature field of ECR with different roll radii: (a) $100 \mathrm{~mm}$; (b) $135 \mathrm{~mm}$; and (c) $150 \mathrm{~mm}$ 


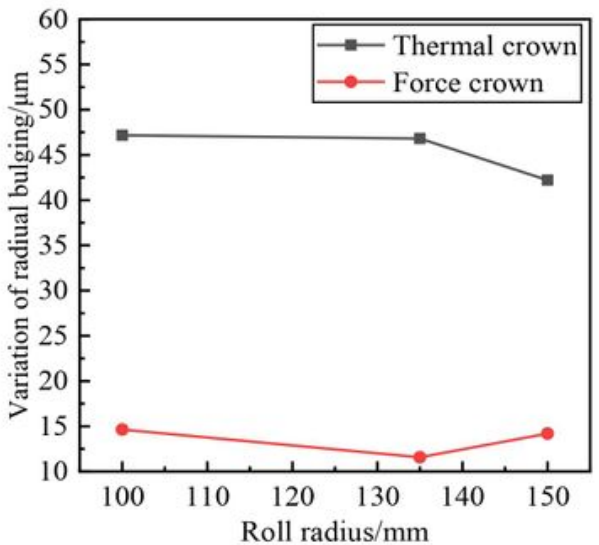

Fig. 12. Thermal crown variation and force crown variation under different roll radii

Figure 12

Thermal crown variation and force crown variation under different roll radii 

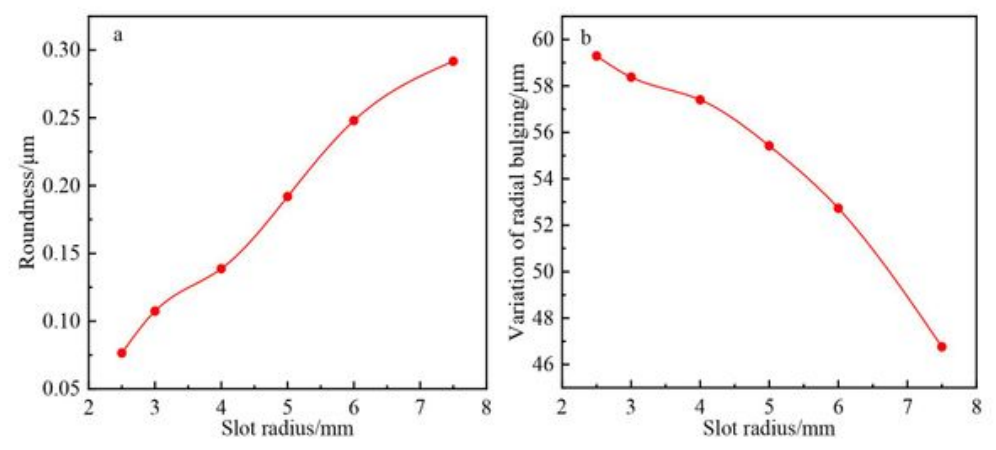

Fig. 13. Status of ECR bulging under different slot radii: (a) roundness and (b) variation in radial bulging.

Figure 13

Status of ECR bulging under different slot radii: (a) roundness and (b) variation in radial bulging 


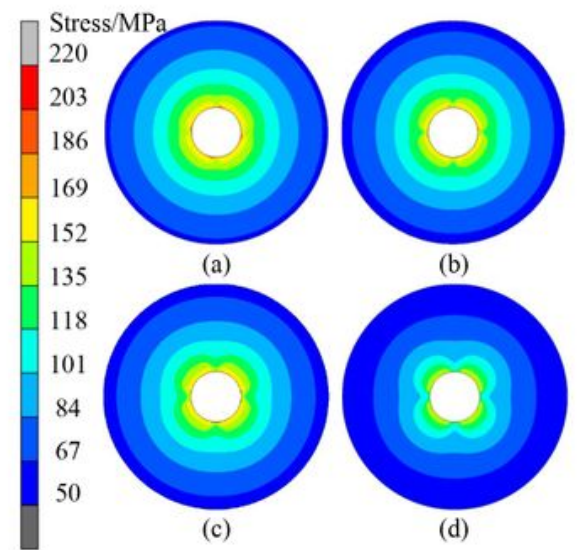

Fig. 14. Stress status of the ECR under different slot radii: (a) slot radius of $2.5 \mathrm{~mm}$, (b) slot radius of $3 \mathrm{~mm}$, (c) slot radius of $5 \mathrm{~mm}$, and (d) slot radius of $7.5 \mathrm{~mm}$.

Figure 14

Stress status of the ECR under different slot radii: (a) slot radius of $2.5 \mathrm{~mm}$, (b) slot radius of $3 \mathrm{~mm}$, (c) slot radius of $5 \mathrm{~mm}$, and (d) slot radius of $7.5 \mathrm{~mm}$ 


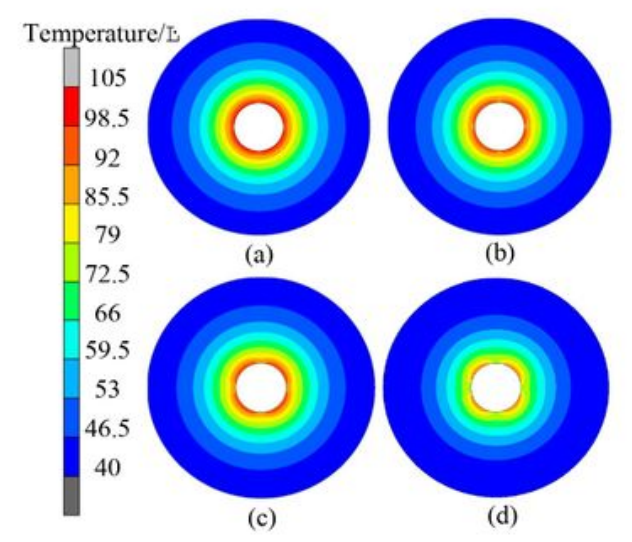

Fig. 15. Temperature field of the ECR under different slot radii: (a) slot radius of 2.5 $\mathrm{mm}$, (b) slot radius of $3 \mathrm{~mm}$, (c) slot radius of $5 \mathrm{~mm}$, and (d) slot radius of $7.5 \mathrm{~mm}$.

Figure 15

Temperature field of the ECR under different slot radii: (a) slot radius of $2.5 \mathrm{~mm}$, (b) slot radius of $3 \mathrm{~mm}$, (c) slot radius of $5 \mathrm{~mm}$, and (d) slot radius of $7.5 \mathrm{~mm}$. 


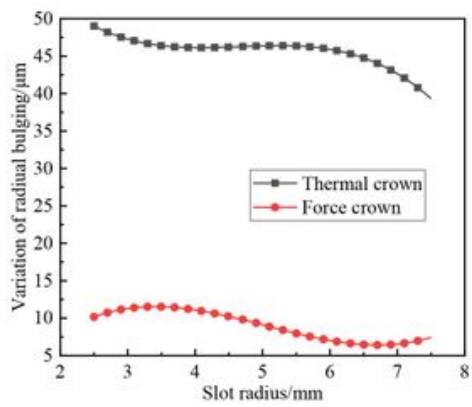

Fig. 16. Thermal crown variation and force crown variation under different slot radii

Figure 16

Thermal crown variation and force crown variation under different slot radii 


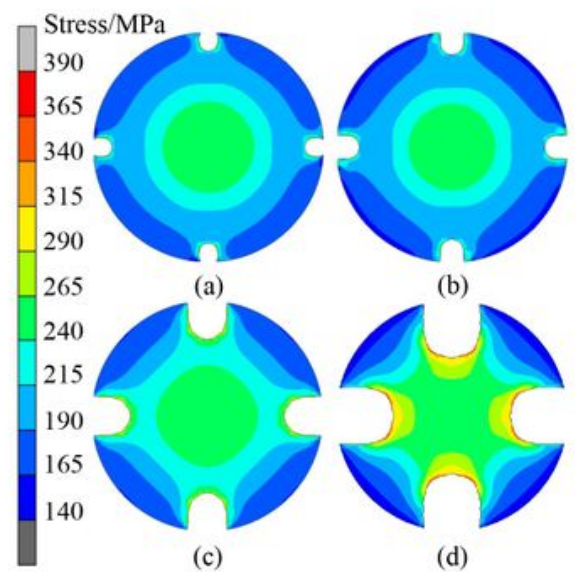

Fig. 17. Stress field of the ES under different slot radii: (a) slot radius of $2.5 \mathrm{~mm}$, (b) slot radius of $3 \mathrm{~mm}$, (c) slot radius of $5 \mathrm{~mm}$, and (d) slot radius of $7.5 \mathrm{~mm}$.

Figure 17

Stress field of the ES under different slot radii: (a) slot radius of $2.5 \mathrm{~mm}$, (b) slot radius of $3 \mathrm{~mm}$, (c) slot radius of $5 \mathrm{~mm}$, and (d) slot radius of $7.5 \mathrm{~mm}$. 

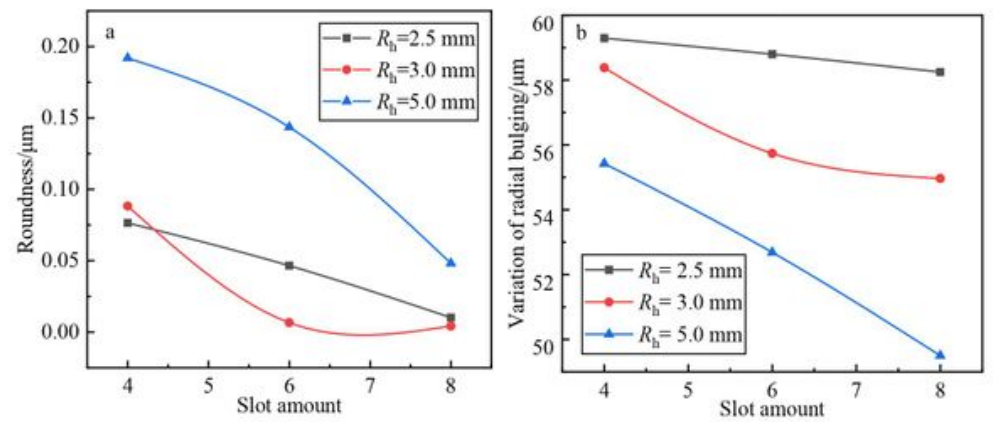

Fig. 18. Status of ECR bulging under different slot amounts: (a) roundness and (b) variation in radial bulging.

Figure 18

Status of ECR bulging under different slot amounts: (a) roundness and (b) variation in radial bulging. 


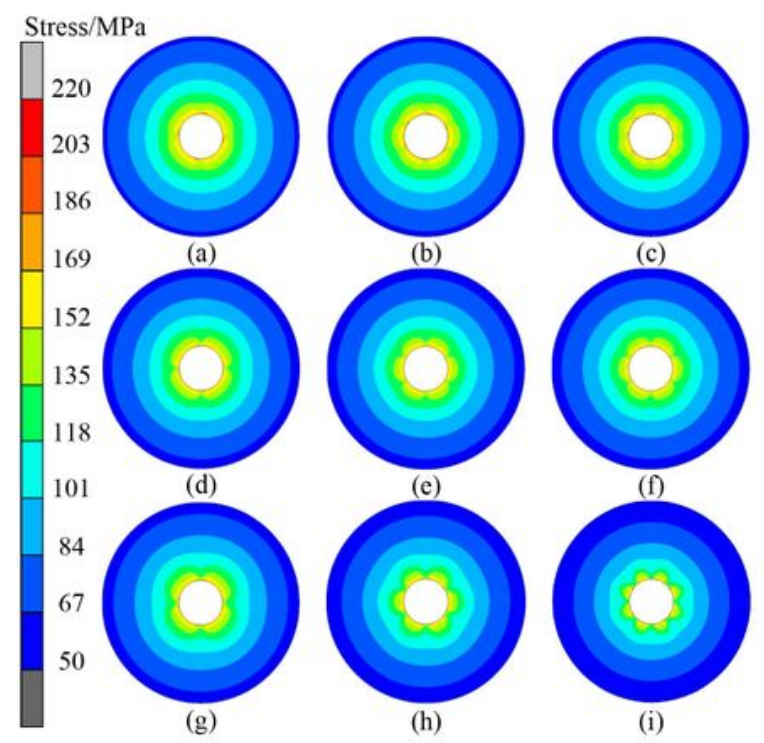

Fig. 19. Stress status of the ECR under different slot amounts: (a) $R_{\mathrm{h}}=2.5 \mathrm{~mm}, N=4$, (b) $R_{\mathrm{h}}=2.5 \mathrm{~mm}, N=6$, (c) $R_{\mathrm{h}}=2.5 \mathrm{~mm}, N=8$, (d) $R_{\mathrm{h}}=5 \mathrm{~mm}, N=4$, (e) $R_{\mathrm{h}}=5 \mathrm{~mm}, N=6$, (f) $R_{\mathrm{h}}=5$ $\mathrm{mm}, N=8$, (g) $R_{\mathrm{h}}=7.5 \mathrm{~mm}, N=4$, (h) $R_{\mathrm{h}}=7.5 \mathrm{~mm}, N=6$, and (i) $R_{\mathrm{h}}=7.5 \mathrm{~mm}, N=8$.

Figure 19

Stress status of the ECR under different slot amounts: (a) Rh=2.5 mm, N=4, (b) Rh=2.5 mm, N=6, (c) $\mathrm{Rh}=2.5 \mathrm{~mm}, \mathrm{~N}=8$, (d) $\mathrm{Rh}=5 \mathrm{~mm}, \mathrm{~N}=4$, (e) $\mathrm{Rh}=5 \mathrm{~mm}, \mathrm{~N}=6$, (f) $\mathrm{Rh}=5 \mathrm{~mm}, \mathrm{~N}=8$, (g) $\mathrm{Rh}=7.5 \mathrm{~mm}, \mathrm{~N}=4$, (h) $\mathrm{Rh}=7.5 \mathrm{~mm}, \mathrm{~N}=6$, and (i) $\mathrm{Rh}=7.5 \mathrm{~mm}, \mathrm{~N}=8$. 


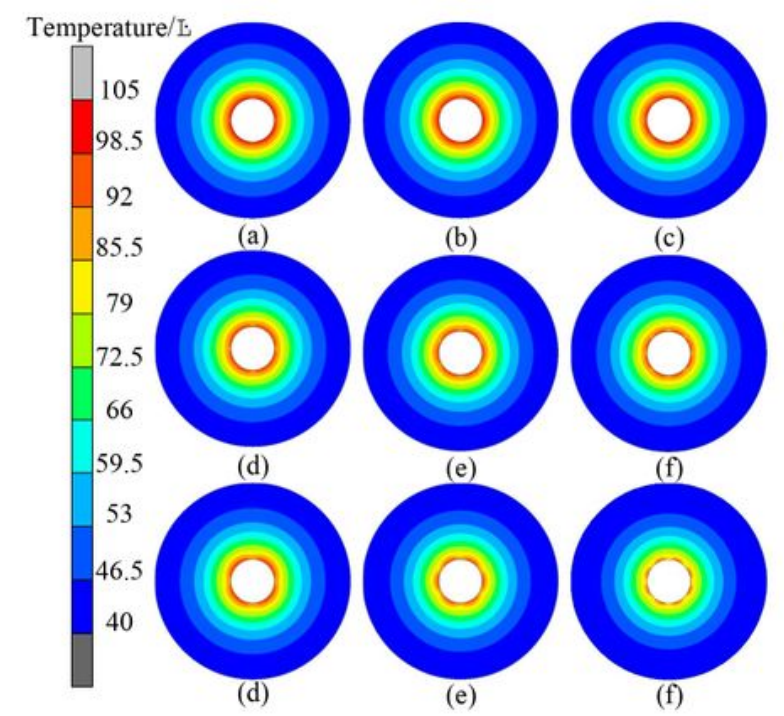

Fig. 20. Temperature field of the ECR under different slot amounts: (a) $R_{\mathrm{h}}=2.5 \mathrm{~mm}$, $N=4$, (b) $R_{\mathrm{h}}=2.5 \mathrm{~mm}, N=6$, (c) $R_{\mathrm{h}}=2.5 \mathrm{~mm}, N=8$, (d) $R_{\mathrm{h}}=5 \mathrm{~mm}, N=4$, (e) $R_{\mathrm{h}}=5 \mathrm{~mm}, N=6$, (f) $R_{\mathrm{h}}=5 \mathrm{~mm}, N=8$, (g) $R_{\mathrm{h}}=7.5 \mathrm{~mm}, N=4$, (h) $R_{\mathrm{h}}=7.5 \mathrm{~mm}, N=6$, and (i) $R_{\mathrm{h}}=7.5 \mathrm{~mm}, N=8$.

Figure 20

Temperature field of the ECR under different slot amounts: (a) Rh=2.5 mm, N=4, (b) Rh=2.5 mm, N=6, (c) $R h=2.5 \mathrm{~mm}, \mathrm{~N}=8$, (d) $\mathrm{Rh}=5 \mathrm{~mm}, \mathrm{~N}=4$, (e) $\mathrm{Rh}=5 \mathrm{~mm}, \mathrm{~N}=6$, (f) $\mathrm{Rh}=5 \mathrm{~mm}, \mathrm{~N}=8$, (g) $\mathrm{Rh}=7.5 \mathrm{~mm}, \mathrm{~N}=4$, (h) $\mathrm{Rh}=7.5 \mathrm{~mm}, \mathrm{~N}=6$, and (i) $\mathrm{Rh}=7.5 \mathrm{~mm}, \mathrm{~N}=8$. 

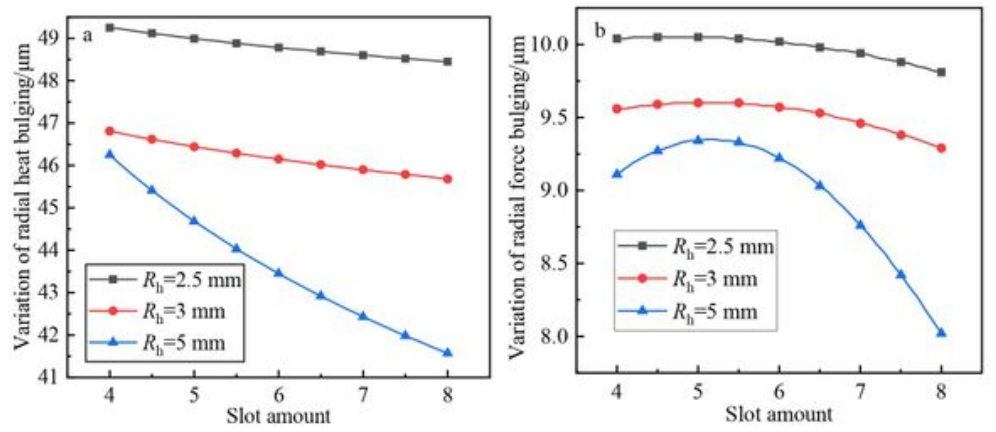

Fig. 21. Thermal crown variation and force crown variation under different slot amounts: (a) thermal crown and (b) force crown.

\section{Figure 21}

Thermal crown variation and force crown variation under different slot amounts: (a) thermal crown and (b) force crown. 